\title{
LA ESPADA DE LA PERLA. ESTUDIO DE LAS EMPUÑADURAS DE REMACHES CON DOBLE ARCO: UN UNICUM EN LA SERIE DE ARMAS EUROPEAS DE LA EDAD DEL BRONCE*
}

\author{
POR
}

\author{
PABLO GÓMEZ RAMOS
}

\section{RESUMEN - ABSTRACT}

El estudio de la espada madrileña de La Perla viene a constatar un modelo único de enmangar espadas en España durante el Bronce Antiguo y Medio, mediante empuñaduras de doble arco. Desde el trabajo clásico de Almagro Gorbea en 1972 sobre la espada de Guadalajara, se han venido sucediendo en estas casi tres décadas, nuevos hallazgos arqueológicos que refuerzan la singularidad del ejemplo español con respecto a otras áreas europeas y que se completa con la investigación de los análisis metalúrgicos realizados a numerosas espadas de la Edad del Bronce.

The study of the Bronze-Age sword from La Perla (Madrid, Spain) shows the development of a unique hilt design in the shape of a double-arch during the Early and Middle Bronze Ages. After the well-known paper by Almagro-Gorbea in 1972 on the Guadalajara sword, new archaeological finds during the last thirty years have shown the singularity of this system as against those employed in other parts of Europe, a singularity confirmed by numerous metallurgical analyses of Bronze Age swords.

\section{PALABRAS CLAVE - KEY WORDS}

Edad del Bronce. Armas. Espadas. Análisis metalúrgicos.

Bronze Age. Weapons. Swords. Metallurgical analysis.

De las piezas rescatadas por Siret a finales del siglo XIX en las excavaciones de los yacimientos argáricos del Sureste, llamó la atención el hallazgo de varias espadas en las tumbas de El Argar y Fuente Álamo, que lógicamente, pasaron pronto a formar parte de los fondos de museos extranjeros. Estudiadas dentro del conjunto de materiales y yacimientos argáricos

* Este trabajo se enmarca dentro del estudio que llevo a cabo sobre metalurgia antigua madrileña, financiado por la Dirección General de Investigación de la Comunidad de Madrid mediante la concesión en 1998 de una Beca Postdoctoral. Estoy en deuda con numerosas personas que de una u otra manera han contribuido con su ayuda en la realización de este artículo. En primer lugar, a la Dra. Concepción Blasco (Universidad Autónoma de Madrid) le debo las observaciones directas de la espada y la financiación de los análisis en uno de sus proyectos de investigación. A la Dra. Carmen Rovira Hortalà (Museo Arqueológico de Barcelona) la obtención de las muestras para la realización de los análisis metalúrgicos. A los Dres. Germán Delibes y Julio Fernández Manzano (Universidad de Valladolid), Dr. Ignacio Montero (C.S.I.C.), Dr. Salvador Rovira (Museo Arqueológico de Madrid), Dra, Catalina Galán, Dr. Dirk Brandherm y M ${ }^{\mathrm{a}}$ Gabaldón (Universidad Autónoma de Madrid) valiosas puntualizaciones y referencias bibliográficas de sus trabajos, algunos de ellos en prensa; y al Dr. Fernando Fernández Gómez (Museo Arqueológico de Sevilla), Dra. Carmen Cacho y a Dña. Ruth Maicas (Museo Arqueológico Nacional de Madrid) la ayuda en la localización de varias espadas de nuestro interés depositadas en dichos museos. 
en 1913 Luis Siret les dedicará un poco más de atención al sistematizarlas con otros ejemplares conocidos en esa fecha, como la espada de Puertollano. Un año después, en 1914, Enrique Leguina daba a conocer tres espadas encontradas en Cuevallusa, Santander, nómina que se fue completando en las décadas siguientes con otros hallazgos fortuitos, pertenecientes en su mayor parte a colecciones particulares como la de Luis Vives, José Bento o Ramón Rodríguez Bauzá y que se depositaron progresivamente en distintos museos españoles. En 1949 Manuel Gómez Moreno en un trabajo sobre lo argárico granadino completaba los datos de Luis Siret con la publicación de otras espadas, desconocidas hasta ese momento. Aparte de otras obras generales no será hasta 1972 con el estudio emprendido por Martín Almagro Gorbea sobre la espada de Guadalajara, cuando se singularice la excepcionalidad de estas y otras armas «argáricas» que completará el autor cuatro años después con la publicación de un nuevo hallazgo proveniente de Entrambasaguas, Santander. Su clasificación tipológica y cronológica fue ampliamente seguida por la investigación posterior, aunque no exenta de críticas por parte de algunos estudiosos (Lull, 1983).

En las últimas décadas, al descubrimiento de nuevas espadas se añade una importante serie de análisis metalúrgicos que permite actualmente, repasar y completar los datos aportados por los investigadores que nos precedieron. Dentro de esta revisión ocupa un lugar importante la espada de la Perla, que es una de las piezas más destacadas de la colección de restos arqueológicos madrileños, reunida por José Bento a principios de siglo y depositada en el Museo Arqueológico de Barcelona. La información inicial sobre esta espada es muy escueta y proviene de la noticia facilitada por José Pérez de Barradas en 1936, quien fue el primero en darla a conocer. Al retomar su estudio hemos constatado dos de las características principales compartidas por las espadas españolas anteriores al Bronce Final. Por un lado, una composición de cobre arsenicado y por otro, la huella de un arco doble de herradura en la cabecera de la hoja. Peculiaridad, que con la puesta al día que hacemos, no se limitó sólo a unas pocas espadas peninsulares sino que posiblemente fue algo genérico a todas ellas, marcando el carácter autóctono de este tipo de empuñaduras con respecto a otras áreas europeas y mediterráneas.

\section{DESCRIPCIÓN Y ANÁLISIS MORFOLÓGICO}

Morfológicamente la espada de La Perla se compone de una hoja metálica plana y ancha, ligeramente pistiliforme, con una estrangulación en el primer tercio del cuerpo. La empuñadura, hoy perdida, se ensamblaba a la hoja mediante tres roblones, aunque presenta otras escotaduras más pequeñas en la parte superior, dos a cada lado a la altura de los remaches y tres más en el comienzo de la hoja, lo que podría significar un número originario de hasta diez remaches. Las medidas dadas por Almagro Gorbea (1972) son de 53,3 cm. de longitud, $9,4 \mathrm{~cm}$. de ancho en la cabeza del empalme, $8,7 \mathrm{~cm}$. de anchura máxima de la hoja y un grosor de $0,4 \mathrm{~cm}$.

Presenta, además de dos pequeñas muescas en el filo de la hoja, posibles indicios de uso, una leve impronta de doble arco de herradura en la zona de empuñadura que había pasado desapercibida en observaciones anteriores con la única excepción de un trabajo de D. Brandherm (1995: 314, $\left.n^{\circ} .1347\right)$. En el examen que C. Blasco ha tenido la amabilidad de realizar de mi parte a la espada en el Museo Arqueológico de Barcelona se ha confirmado la apreciación primera de este investigador alemán. Sin embargo, estas marcas dejadas por la empuñadura original no son exclusivas de esta espada y ya desde principios de siglo se han mencionado o dibujado otros ejemplares con señales idénticas o muy similares. Las empuñaduras de las espadas, se han perdido en su inmensa mayoría, lo que indica que serían de materia orgánica, principalmente de madera. Los hermanos Siret en sus excavaciones en el Sureste penin- 
sular, recogieron abundantes pruebas materiales de armas argáricas, sobre todo puñales, que conservaban aún los restos de madera de los puños ${ }^{1}$. A su vez, el alma de madera pudo tener un recubrimiento metálico en oro o plata que diera mayor prestancia a unas armas sumamente escasas en comparación con el elevado número de otras armas más cortas como puñales o alabardas. El ejemplo más representativo de recubrimiento de un mango de madera con láminas de oro lo ostenta la espada de Guadalajara, aunque como veremos, no debió ser un caso aislado.

El ensamblaje entre la empuñadura y la hoja se realizaba mediante roblones metálicos de cobre, bronce o plata que una vez que traspasaban las empuñaduras eran machacados para unir ambas partes y de los cuales hay multitud de ejemplos, no sólo en espadas sino también en puñales, cuchillos o alabardas. Algunos roblones, o incluso clavetas de madera, seguramente más pequeños e internos, que aseguraran una mayor sujeción de las partes, quedarían tapados o disimulados por la empuñadura misma con objeto de evitar un resultado final poco estético. En este sentido podrían interpretarse las pequeñas escotaduras que a ambos lados de la hoja y en la parte superior aparecen en la espada de La Perla, huecos dejados quizá, por otros remaches de menor tamaño.

La relación de espadas con remaches y lengüeta simple de la Edad del Bronce peninsular con improntas de arcos dobles de forma de herradura o de medio punto en la cabecera de la hoja (Figura 1), presentada por Siret (1913), Gómez Moreno (1949) y Almagro Gorbea (1972 y 1976) y completada con otros hallazgos más recientes, es la siguiente:

Espada de La Perla (Madrid): la espada objeto de este estudio presenta una huella en forma de arco doble de herradura que no mencionó ni Pérez de Barradas (1936) ni Almagro Gorbea (1972).

Espada de Villaviudas I (Palencia): longitud 48,6 cm.; anchura máxima de la hoja 7,2 $\mathrm{cm}$. y en la zona de la empuñadura $9 \mathrm{~cm}$. Número de seis remaches en origen, de los cuales sólo se conservan tres. Ofrece un estrangulamiento en el talón de la hoja justo inmediatamente después del ensanche de la empuñadura y son claros los arcos de herradura (Palol, 1969: 296).

Espada de Villaviudas II (Palencia): longitud $51 \mathrm{~cm}$.; anchura de la hoja 5,8 y en la parte de la empuñadura $7,2 \mathrm{~cm}$. Comparte varias características con la espada anterior como son los tres remaches actuales de un número originario de seis, el estrechamiento en el talón de la hoja, aunque en este caso es menos marcado y también dos improntas de arcos de herradura perfectamente visibles (Rodríguez et alii, 1988: 221, fig. 1).

Espada de Guadalajara: longitud 52,5 cm.; 5,8 cm. de ancho en la cabeza de la hoja; 8,7 $\mathrm{cm}$. de anchura máxima y con un ligero estrechamiento en parte superior de la hoja. Excepcionalmente la espada de Guadalajara conservaba la empuñadura, hecha de madera y forrada de oro, y aunque restaurada posteriormente, parece ser originaria a la espada de la Edad del Bronce. Según un estudio reciente (Brandherm, 1998) esta espada contó con dos empuñaduras distintas; la primera de ellas ya dejó impresas las señales en forma de doble herradura que luego aparecerían en el repujado de la empuñadura de oro y que indican que podría tratarse de modelos de perduración muy larga. Pero igualmente destacable es el hecho de que la espada de Guadalajara con empuñadura chapada en oro formaba parte de un conjunto perteneciente a la colección Rodríguez Bauzá, compuesto por el fragmento de otra empuñadura chapada de oro y otras dos hojas de espadas, una de ellas señalada como espada del Museo Arqueológico Nacional (Almagro Gorbea, 1972: 65, fig. 4.3). Las otras dos hojas, aparecen denominadas aquí como Rodríguez Bauzá II y III, porque pertenecían a la misma colección y quizá tenían también la misma procedencia que la espada de Guadalajara.

1 Numerosos puñales y cuchillos de El Argar conservaban todavía astillas y restos de madera de los mangos, entre los pasadores metálicos, por ejemplo, las armas de las sepulturas número 5, 208, 314, 400, 497, etc. (Siret, 1890: lám. 29 y ss). 
Espada Rodríguez Bauzá II: longitud parcial $51,7 \mathrm{~cm}$. y anchura máxima 4,9 cm. Aunque está incompleta en su parte distal, y la cabeza donde se acoplaría la empuñadura está rota, si se pueden observar todavía huellas en forma de doble herradura como ya señalara Almagro Gorbea (1972: 65, fig. 4.3). Posiblemente esta hoja y la empuñadura de oro número dos de la colección Rodríguez Bauzá conformaran en su día una sola pieza (Brandherm, 1998: 179). En esta línea, una de las chapas áureas del tesoro conquese de Abía de la Obispalía, identificada como resto de la empuñadura de una espada o puñal, presentaba dos escotaduras en forma de doble arco de herradura como motivo decorativo y evolución por lo tanto, de arcos dobles funcionales (Almagro Gorbea, 1972: 75 y 1974: 44-45).

Espada Rodríguez Bauzá III: se trata de una hoja de dimensiones menores con una longitud de sólo 35,2 cm. Tiene dos huellas de empuñaduras superpuestas, ambas de doble herradura de las cuales de la primera sólo se conserva una parte (Brandherm, 1998: 183 y fig. 1). A diferencia de la espada de Guadalajara en estas otras dos espadas de Rodríguez Bauzá no se observan estrechamientos bruscos de la hoja.

Espada de Puertollano (Ciudad Real): $47 \mathrm{~cm}$. de longitud y algo más de $6 \mathrm{~cm}$. de anchura máxima. Presenta roto el extremo distal por lo que su longitud debió acercarse a los 60 $\mathrm{cm}$. Aparece tachonada con seis roblones de plata, cuatro en línea y dos más pequeños en los bordes. Depositada en el Museo Arqueológico Nacional, sólo Siret refiere escuetamente su procedencia de una sepultura del Cerro de San Sebastian (Siret, 1913: 383, nº. 2, fig. 151). $\mathrm{Al}$ igual que ocurrió con la espada de La Perla, cuyas improntas pasaron desapercibidas para los investigadores, la espada de Puertollano presenta dos arcos que no recogieron ni Siret (1913: 383, fig. 151, $\mathrm{n}^{\circ}$. 2) ni Gómez Moreno (1949: 338, fig. 3) pero sí Almagro Gorbea (1972: 63, fig. 3.3) aunque no los describe.

Espada de Linares (Jaén): longitud 58 cm.; anchura en la zona del empalme 7,6 cm. Tiene cinco remaches, tres de ellos en línea y otros dos más pequeños en los extremos laterales. Cuenta con un ligero estrechamiento de talón y dos huellas en forma de arcos de herradura más completos en el dibujo de Almagro Gorbea (1972: 63, fig. 3.5) que en el de Gómez Moreno (1949: 338, fig. $\mathrm{n}^{\circ}$. 2) que es quien la recoge inicialmente.

Espada del Rincón de Almendricos de Lorca (Murcia): longitud de $33 \mathrm{~cm}$. y anchura máxima de $8,8 \mathrm{~cm}$. La hoja posee cinco remaches dispuestos en semicírculo que la unían a la empuñadura que dejó señales claras de dos arcos de herradura. Apareció en el interior de una cista junto con una alabarda tipo Argar, formando parte del ajuar de un difunto (Ayala, 1991: 103, 131-132, fig. 36).

Espada de El Argar tumba 429 (Almería): longitud $52 \mathrm{~cm}$. de largo por 6,5 cm. de anchura en la cabeza. Tiene cuatro remaches en línea y otros dos roblones de menor tamaño en los bordes. Presenta estrechamiento de talón así como rastro de dos arcos, rebajados para Almagro Gorbea (1972: 63, fig. 3.1) y claramente de medio punto en la última revisión de Schubart y Ulreich (1991, tafel 29).

Espada de El Argar tumba 824 (Almería): longitud 54,5 cm. y $5 \mathrm{~cm}$. de anchura máxima (Almagro, 1972: 64). Otras fuentes anteriores dan como longitud de esta espada $65 \mathrm{~cm}$. (Siret, 1890: 183; Siret, 1913: 383). Tiene seis remaches, cuatro en línea y dos roblones más pequeños justo debajo de los dos de los extremos. Al igual que la anterior se ve un estrechamiento de la hoja en la zona del talón y una huella clarísima de dos arcos de herradura perfectamente definidos (Schubart y Ulreich, 1991: tafel 55).

Espada de Montejícar (Granada): longitud $59 \mathrm{~cm}$. y 5,6 cm. de anchura máxima. Conserva dos arcos de medio punto, «senos cóncavos» en palabras de Gómez Moreno y tiene como particularidad dos roblones en el centro que se completarían con otros cinco remaches de los cuales sólo quedan los taladros en el inicio de la hoja (Gómez Moreno, 1949: 339). 


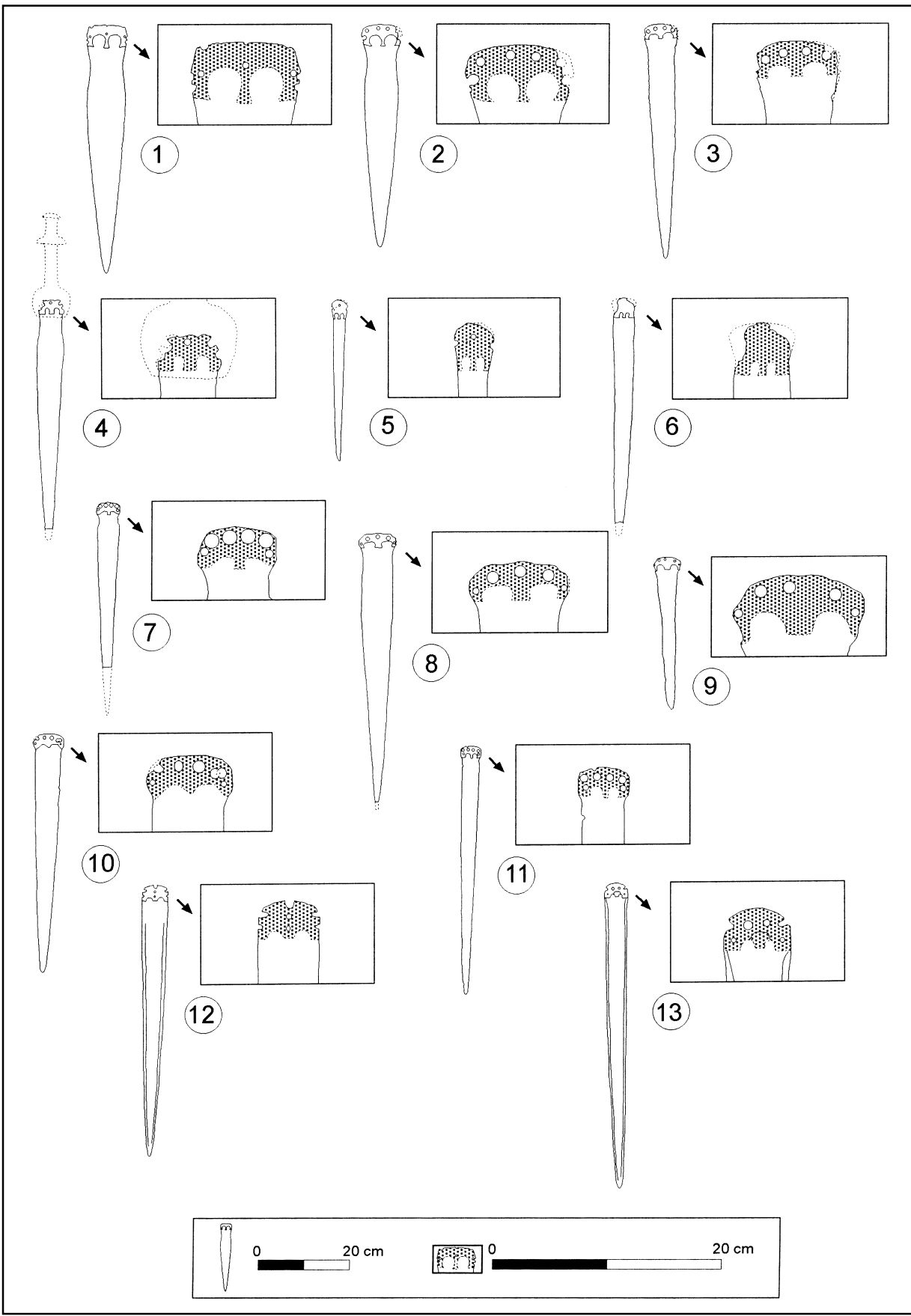

Figura 1. Espadas con marcas dobles de arcos de herradura o medio punto: 1. La Perla (Brandherm, 1995). 2. Villaviudas I (Palol, 1969). 3. Villaviudas II (Rodríguez et alii, 1998). 4. Guadalajara (Brandherm, 1998). 5. Rodríguez Bauzá II (Brandherm, 1998). 6. Rodríguez Bauzá III (Brandherm, 1998). 7. Puertollano (Almagro Gorbea, 1972). 8. Linares (Almagro Gorbea, 1972). 9. Rincón de Almendricos (Ayala, 1991). 10. El Argar 429 (Schubart y Ulreich, 1991). 11. El Argar 824 (Schubart y Ulreich, 1991). 12. Montejícar (Gómez Moreno, 1949). 13. Forcas (Harbison, 1967). 
Espada de la Cueva de las Ventanas (Granada): recientemente se ha dado a conocer el hallazgo en esta cueva del término municipal de Piñar, de una espada procedente de una tumba expoliada que presenta una huella clarísima de doble arco con restos de cuero perteneciente a la empuñadura (Riquelme, 1999).

Además de estas espadas existen otros ejemplares que en vez de arcos de herradura, presentan, según dibujos, huellas de arcos dobles más rebajados, a veces solamente insinuados (Figura 2), como son:

Espada de Cuevallusa I (Santander): su longitud actual es de $42,2 \mathrm{~cm}$., pues presenta roto el extremo distal de la hoja. Tiene seis roblones, un marcado estrechamiento en el talón de la hoja y por su morfología externa es muy similar a la espada de La Perla. Es la única espada de arcos que cuenta con decoración estriada a lo largo de la hoja y una pequeña espiga para fijar a la empuñadura, lo que llevó a Almagro Gorbea a relacionarlas acertadamente, más con armas bretonas que con los modelos argáricos (Almagro Gorbea, 1972: 61-62, fig. 2.1).

Espadas de Cuevallusa II y III (Santander): longitud de 50 y $42 \mathrm{~cm}$. con cuatro y seis remaches respectivamente, aunque debieron tener en origen un número mayor por las escotaduras conservadas. Al igual que la espada anterior tienen hojas con estrechamientos marcados, sobre todo, la primera. Hay destacar que las tres espadas de Cuevallusa, según una noticia que luego no ha trascendido, tenían remaches de plata (Leguina y Vidal, 1914: 55). Aunque estas dos espadas no llevan, según los dibujos y fotografías existentes, decoración en la hoja, se ha señalado que fueron estudiadas previamente a su limpieza (Leguina y Vidal, 1914; Almagro Gorbea, 1972).

Espada de Entrambasaguas (Santander): longitud de $61 \mathrm{~cm}$. y anchura en la parte de la cabeza de $6,5 \mathrm{~cm}$. El número de remaches original sería seis, cuatro en línea y dos más pequeños en los bordes. Conserva una leve impronta de un doble arco rebajado en la zona de la empuñadura, aunque sólo queda parte de uno (Almagro Gorbea, 1976: 458-459).

Espada de Cabeza Gorda de Totana (Murcia): longitud de 60,4 cm. y anchura máxima de $5,4 \mathrm{~cm}$. Posee seis remaches, cuatro más o menos en línea recta y otros dos más pequeños a los lados, repitiendo modelos ya vistos en otras espadas argáricas. En el dibujo publicado de esta espada se observan marcas de arcos rebajados. Apareció formando parte de un ajuar funerario en una cista del poblado (Ayala y Tudela, 1993: 19, fig. 2).

Espada de la sepultura 9 de Fuente Álamo (Almería): $58 \mathrm{~cm}$. de largo y $6,3 \mathrm{~cm}$. de ancho en la cabeza. Número de remaches seis, cuatro más o menos en línea y dos más pequeños en los bordes. Presenta, también según dibujos, dos arcos deprimidos (Almagro Gorbea, 1972: 63, fig. 3.2). Se halló en un enterramiento, en concreto, cruzada sobre el pecho del difunto (Siret, 1890: 260).

Espada del Castillejo de Atarfe (Granada): longitud 62,5 cm. y 8 de ancho. Número de remaches originales siete. Conserva arcos rebajados que no fueron señalados ni por Vázquez de Parga (1935, lámina I), ni tampoco por Gómez Moreno (1949: 338, nº 1) pero sí por Almagro Gorbea (1972: 63, fig. 3.4).

Espada de La Herradura (Granada): longitud de $67 \mathrm{~cm}$. y 8,10 cm. de ancho en la zona del enmangue. El número original de remaches era de siete. Encontrada en una cista funeraria, a pesar de su nombre, tiene, según los autores del estudio dos arcos rebajados no excesivamente visibles en el dibujo de la pieza (Ruiz Morales y Molina Poveda, 1996: 177).

Espada de Setefilla (Sevilla): quizá deba incluirse en este inventario un estoque, de 50,2 $\mathrm{cm}$. de longitud y cuatro remaches, porque aunque en los estudios referidos al yacimiento (Aubet y Serna, 1981; Aubet et alii, 1983) sólo se menciona que la empuñadura tuvo una base

2 Existe una espada corta hallada por los Siret en la sepultura 1 de Fuente Álamo, que también presentaba ornamentación estriada consistente en cuatro líneas huecas señaladas a lo largo de la hoja (Siret, 1890: lám. 66). 


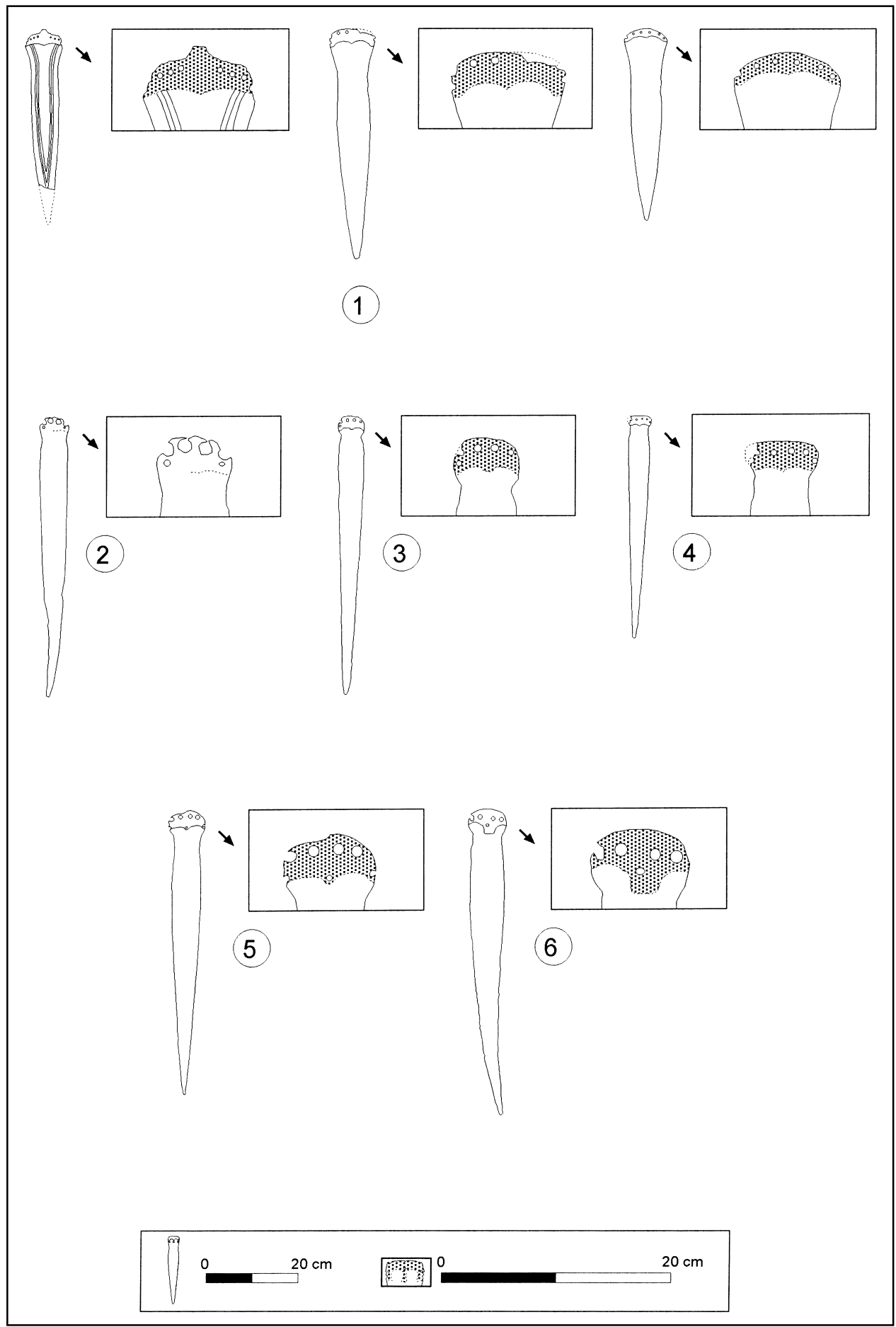

Figura 2: Espadas con marcas dobles de arcos rebajados: 1. Cuevallusa I, II y III (Almagro Gorbea, 1972). 2. Entrambasaguas (Almagro Gorbea, 1976). 3. Cabeza Gorda de Totana (Ayala y Tudela, 1993). 4. Fuente Álamo (Almagro Gorbea, 1972). 5. Atarfe (Almagro Gorbea, 1972). 6. La Herradura (Ruiz y Molina, 1996). 
sinuosa, en una observación atenta a las láminas de esta espada, puede distinguirse en el lado izquierdo, parte de uno de los dos arcos, muy cerrados y morfológicamente similares a los de la espada de Puertollano. Se trata sin embargo, de una apreciación personal sensu videndi y que por lo tanto, habría que confirmar.

Si bien tipológicamente corresponde al Bronce Final hay que destacar la espada de Forcas (Orense). Hallada en una cueva artificial en Tucela, es una espada de remaches de 67,4 cm. de longitud y $4,4 \mathrm{~cm}$. de ancho, dos en línea en la parte superior, otros dos a los lados y dos agujeros más, restos de otros pasadores. Lo más interesante son las improntas de dos arcos de herradura enmarcados dentro de un arco mayor (Harbison, 1967: 101, fig. 1.2) quizá porque en su día llegó a contar con dos empuñaduras distintas. Otros trabajos anteriores al de Harbison (Ferro Couselo, 1941: 121 y lám. XLVIII; Gómez Moreno, 1949: 40) y posteriores (Almagro Gorbea, 1972: 65, fig. 4.5; 1976: 466, fig. 6) no recogieron el dibujo del doble arco.

En la bibliografía aparecen recogidas otras espadas de lengüeta simple y remaches, adscritas de forma genérica al Bronce Medio que no presentan, según dibujos, improntas dobles en la zona de la empuñadura. Me refiero a tres espadas cortas del yacimiento granadino de El Zalabí de Alcudia de Guadix (García Sánchez y Carrasco Rus, 1979: 243, fig. 2) confundidas por la investigación posterior con los puñales de Cerro del Culantrillo, la espada de Cortes de Baza de la colección Hubert Meersmann (García Sánchez y Carrasco, 1979: 244, fig. 3), también de Granada, la espada de Montefrío con un pasador de plata (Siret, 1913: 381), la espada leonesa de Cea (Delibes, Avello y Rojo, 1982: 160, fig. 3), un estoque palentino de cobre arsenicado de la colección Fontaneda (Rovira et alii, 1997: 300; Delibes et alii, 1999), la burgalesa de Santa Olalla de Bureba (Almagro: 1972: 61-62, fig. 2.3), la pontevedresa de Moaña (Gómez Moreno, 1949: 338) y las espadas portuguesas de Bartolomeu do Mar en Braga (Harbison, 1967: 101, fig. 1.3) y Castelo Bom de Belem (Castro Nunes y Vasco Rodrigues, 1957: 281). A este listado cabría añadir otra espada argárica originaria de un poblado manchego y depositada actualmente en una colección particular de Lorca, de la que sólo existe una brevísima referencia (Ayala y Tudela, 1993: 20), una espada de procedencia desconocida de $52 \mathrm{~cm}$. de longitud aunque con los extremos proximal y distal rotos, depositada en los almacenes del Museo Arqueológico Nacional, que es casi idéntica a la hoja Rodríguez Bauzá II aunque lleva otro número de inventario (1964/28/1) y otras dos espadas cortas de cobre pobremente arsenicado, una de El Argar, sepultura 994, en el Museo Arqueológico Nacional $^{3}$ (Rovira et alii, 1997: 46) y la otra, proveniente de Trebujena, Cádiz, hoy en el Museo Arqueológico de Sevilla ${ }^{4}$ (Rovira, et alii, 1997: 141 y 350, fig. 32).

En espera de una comprobación más segura de alguno de estos ejemplares, el inventario de espadas y pomos de la Edad del Bronce con huellas de marcas de arcos dobles en la cabecera de las hojas suma actualmente un total de 22 espadas, 24 si incluimos las de Setefilla y Forcas. Todo este conjunto agrupa espadas con empuñaduras independientes unidas mediante remachado a hojas planas, sin nervaduras y excepto un caso, sin decoración alguna. Almagro Gorbea (1972) hizo una clasificación de dos tipos principales y siete subgrupos, basándose principalmente en las dimensiones, formas de las hojas y en la disposición de los remaches, siendo los tres ejemplares de Cuevallusa, Villaviudas I y La Perla, las más antiguas, clasificadas dentro de un grupo general denominado I. Este grupo evolucionaría progresivamente hacia espadas cada vez más largas, estilizadas y con una tendencia menos marcada a lo pistiliforme dando lugar al grupo II, donde se integrarían el resto de las espadas. A gran-

3 En la observación directa que hice a esta espada en el museo, aprecié restos de una posible marca doble pero desgraciadamente es una pieza muy restaurada y la capa de barniz que la protege impide determinarlo con total seguridad.

4 Según la fotografía de la ficha de inventario, que amablemente me ha enviado el director del Museo Arqueológico de Sevilla, Dr. Fernando Fernández Gómez, se trata de una espada corta o puñal de espigo y remaches, de 32 cm., morfológicamente muy similar a otros hallazgos del norte de la Península Ibérica como la espada leonesa de Sabero (Delibes et alii, 1982: 155, fig. 1) o el puñal asturiano de Puerto Gumial (Blas Cortina, 1983: 113-115, fig. 29.6). 
des rasgos, esta tipología cuenta con la coherencia que da, si no tanto, las medidas o el número de remaches, si desde luego, la morfología genérica de las hojas.

Las improntas de arcos, que podríamos definir como típicamente de herradura, corresponden a las espadas de La Perla, El Argar 824, Rincón de Almendricos, Guadalajara, Rodríguez Bauzá I-II y Villaviudas I, mientras de las de Montejícar, Linares y Villaviudas II tienen marcas de medio punto iguales. Sin embargo, aparte de la característica común del arco doble, ya sea de herradura o no, es difícil establecer una tipología que solucione, principalmente, problemas cronológicos o de fabricación como ya señalara Lull en 1983. De momento, no parece existir correlación entre marcas dobles y tamaño de hoja. Improntas de este tipo presentan espadas cortas como la del Rincón de Almendricos de $33 \mathrm{~cm}$. o Rodríguez Bauzá III que aunque esté incompleta no debió pasar de los $40 \mathrm{~cm}$. y espadas más largas como las de El Argar 824 o Montejícar de unos $60 \mathrm{~cm}$. de longitud. Tampoco parece decisivo el número de remaches, pues todas presentan huellas de arcos dobles independientemente de la cifra de pasadores aunque como adelantó Lull (1983: 158) todas cuentan de cinco a siete remaches, incluida la espada madrileña de la Perla que conserva tres pero debió tener alguno más si consideramos las escotaduras como huecos donde se alojaron otros roblones. Al margen de la longitud de las hojas, lo cierto, es que las espadas del grupo I se diferencian claramente del resto al presentar un estrangulamiento más marcado de la hoja, ya que la disposición de los remaches es menos definitoria al compartir el esquema de cuatro en línea y dos en los extremos, espadas muy distintas como la de Puertollano, Villaviudas I y II o Argar 429.

Las espadas con contexto arqueológico seguro aparecieron en tumbas (Rincón de Almendricos, El Argar, Fuente Álamo, Cabeza Gorda, La Herradura, Cueva de las Ventanas y Setefilla). Sin embargo, el número más importante, como la misma espada de La Perla, corresponde a piezas sin ubicación arqueológica directa a pesar de que se relaciona de forma imprecisa con unas cerámicas. Quizá la alusión de Pérez de Barradas (1936: 49) de que en algunos puntos la espada madrileña conservaba aún señales de tejidos, podría indicar que esta espada tuvo también un final funerario. Son muchas las armas argáricas que formando parte de ajuares, conservaban claramente trazas de fibras o tejidos en la hoja, en la empuñadura de madera e incluso en algunos casos hasta fragmentos físicos de tela adheridos al arma (véase entre otros, Siret, 1890: passim o Simón García, 1988: 58 y 69, $\mathrm{n}^{\circ}$. 6). Estos vestigios podrían interpretarse, tanto como grabados de la vestimenta del difunto durante la descomposición del material (aunque la espada de la tumba 9 de Fuente Álamo no presenta tela grabada en su superficie, si lo hicieron otros puñales de la misma sepultura) como que muchas de estas piezas fueron envueltas en lienzos a la hora de depositarse en la tumba (Hundt, 1991: 425-429; Jover y López, 1997: 63-64), sin poder descartarse que sean impresiones dejadas por vainas, destinadas a proteger el filo de armas cortantes y a dar prestancia a las espadas. Aunque por su carácter perecedero no se conservan vainas que no sean de metal (Dechélette, 1910: 215, fig. 67) si hay ejemplos, un par de ellos en la Península, de otros elementos complementarios de protección como son las conteras. En este sentido, la espada de La Herradura conserva en la punta de la hoja la marca de una contera (Ruiz Morales y Molina Poveda, 1996: 177) seguramente de metal, como constata otro ejemplo, aparecido en Pic dels Corbs, perteneciente al Bronce Final avanzado (Barrachina y Neumaier, 1996: 198, foto 1).

En cuanto a la distribución geográfica (Figura 3) estas espadas se extienden a lo largo de la Península en un eje norte-sur pudiendo establecerse tres grandes focos de los que queda fuera Portugal donde no se han hallado al menos que sepamos, items similares, si bien las estelas decoradas del Alemtejo demuestran que existieron. Por un lado, espadas en el solar geográfico propio de lo argárico, el Sureste español, Murcia, Almería, Granada o Jaén, respectivamente para las espadas de Cabeza Gorda, Rincón de Almendricos, El Argar, Fuente Álamo, Atarfe, Cueva de las Ventanas, Montejícar, La Herradura y Linares, con dos espadas algo más alejadas de esta órbita, la espada de Setefilla y la de Puertollano. La zona centro 
peninsular, Palencia, Guadalajara, Madrid y Ciudad Real, con las dos espadas de Villaviudas, las espadas Rodríguez Bauzá del Museo Arqueológico Nacional y la espada de La Perla. $\mathrm{Y}$ un tercer núcleo representado en Cantabria por las tres espadas de Cuevallusa y Entrambasaguas. Espadas gallegas como la de Forcas, aunque de un momento posterior, indican una expansión generalizada del modelo de arco duplicado, que pudo ser mayor de la que hacemos ahora de forma orientativa basándonos sólo en los hallazgos actuales. Comparto la opinión de Lull (1983: 172) que la utilización de remaches y las huellas dejadas por los mangos, comunes a todas estas espadas no son argumentos suficientes para demostrar que unas derivan de otras. Pero sí creo que la solución de enmangues con forma de arcos dobles (de herradura, medio punto o rebajados) es sumamente significativa, máxime si consideramos que se trata de una singularitas hispana, como también viera en su día Almagro Gorbea (1972: 75), no constatada hasta la fecha, al menos de forma genérica y continuada, en ningún otro lugar fuera de España.

Los contactos o la dispersión, si no de artesanos, sí por lo menos de una idea general y común de enmangar estas armas en la Península durante el Bronce, es algo indiscutible. En toda Europa y el Mediterráneo, durante la Edad del Bronce menudea la utilización de remaches y puños independientes a la hoja, pero los broncistas optaron por empuñaduras de un sólo arco para anclar ambas partes. Almagro Gorbea (1972: 75) presentaba como paralelo continental del arco de herradura, único, durante el Bronce Medio la espada del tipo Cheylonnet de Jugnes, Aude. Existen ya en el Bronce Antiguo y por influencias micénicas, espadas con un arco de herradura en depósitos centroeuropeos como ejemplifican las piezas de abigarrada decoración del depósito rumano de Apa (Gimbutas, 1965: 62, fig. 26, nº 3 y 4). Hallazgos que abundan en mayor número durante el Bronce Medio, sobre todo, en sus últimos momentos, como son, entre otros ejemplos, las espadas de los depósitos húngaros de Zájta y Hajdusámson (Gimbutas, 1965: 78, fig. 39, nº 1; 216, fig. 146, nº. 1), las espadas italianas con empuñadura circular maciza del tipo de Cascina Ranza o empuñaduras octogonales tipo Rovereto, todas ellas con un único arco de herradura (Peroni, 1970: 98 y ss., tafel 41) y que tendrán también su continuidad en otras espadas de la cultura de los Campos de Urnas en Centroeuropa, ya durante el Bronce Final y también durante la Edad del Hierro con las espadas de antenas, pero repitiendo siempre el mismo modelo de un único arco.

Sin embargo, empuñaduras con un arco de herradura no son privativas de espadas ni tampoco del Bronce Medio ya que existen puñales con arco de herradura o arco rebajado durante el Bronce Antiguo prácticamente en toda Europa, incluida la Península Ibérica. En el Bronce Antiguo francés pertenecientes sensu lato a la cultura del Ródano (Guilaine, 1972: 54-55, fig. 11; Roudil, 1972: 50, fig. 14), en grupos culturales del Bronce Antiguo italiano de Polada, Montemerano o Ripatransone (Peroni, 1971: passim), y en la cultura británica de Wessex (Gerloff, 1975: passim). En la Península Ibérica el arco de herradura simple marcó el enmangue de puñales como puede verse entre otros muchos ejemplares en El Argar (Siret, 1890: lám. 29)5. Existe sin embargo un puñal de $21 \mathrm{~cm}$. de longitud encontrado en una sepultura del Cerro de la Encantada (Ciudad Real) que según el dibujo publicado (Nieto y Sánchez Meseguer, 1980: 100, fig. 40, d) podría presentar una marca de doble herradura como confirma Brandherm (e.p.) en el dibujo de esta pieza que estudió de primera mano.

Todos estos ejemplos de espadas y puñales del Bronce Antiguo y Medio europeo se distinguen claramente de las espadas peninsulares en que no son arcos dobles. Las centroeuropeas del Bronce Medio de la cultura de los Túmulos (Novák, 1975: 13, tafel 6) o las italianas coetáneas de los tipos Castions di Strada, Casier y Tèor (Peroni: 1970: 38-50, tafeln 13-14) presentan una decoración de círculos concéntricos formando dobles espirales en la guarni-

5 E. Cartailhac (1886: 224, figs. 312 y 313) recoge dos puñales tipo Ródano, con mango macizo remachado y arco de herradura, al parecer, procedentes de España. 
ción, pero toda vinculación sería forzada ya que son espadas morfológicamente distintas a las peninsulares con empuñaduras de lengüeta tripartita y puntas de lengua de carpa que conforman piezas de una sola lámina obtenida de verter el metal en los moldes.

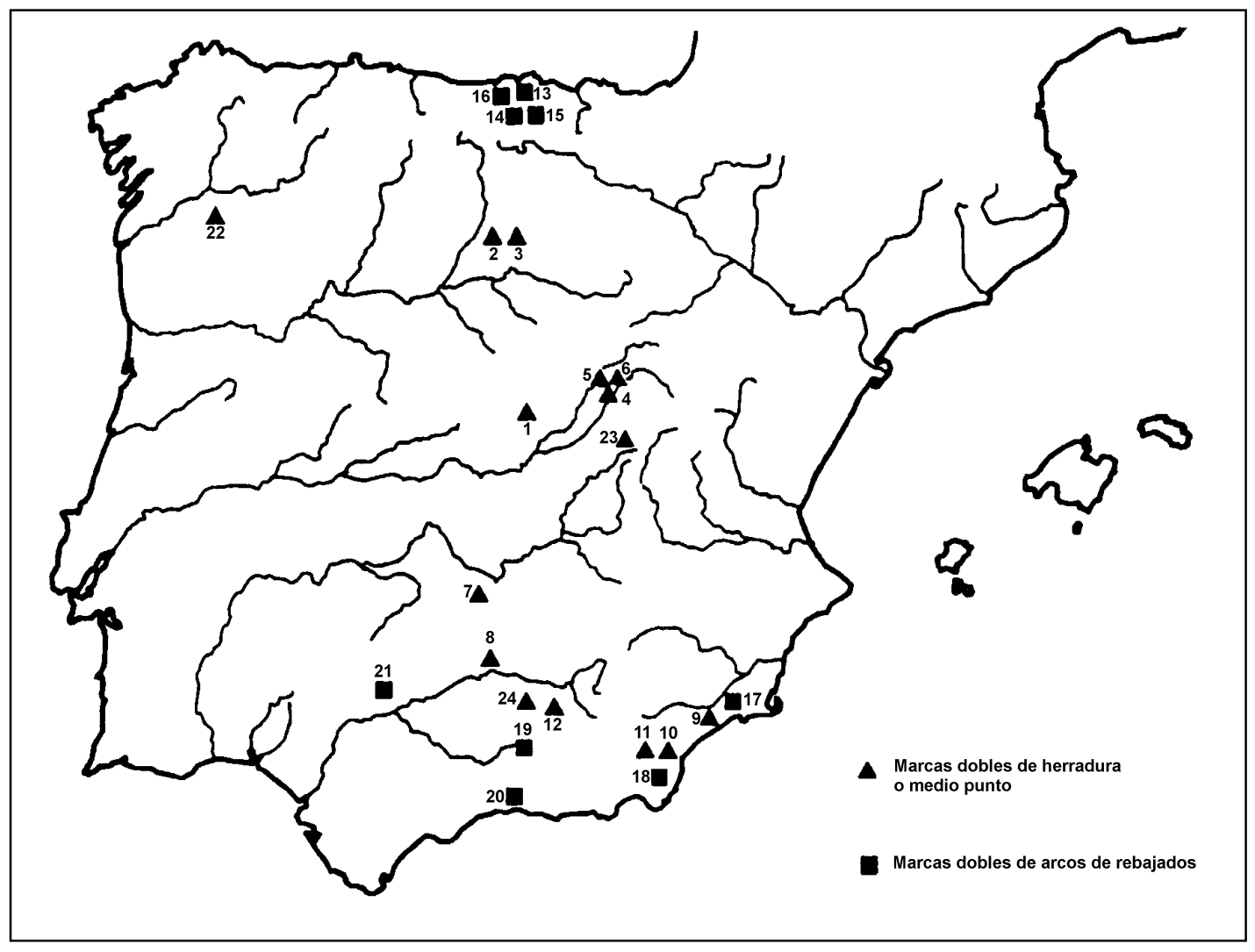

Figura 3: Dispersión de espadas con arcos en España durante la Edad del Bronce: 1. La Perla (Madrid). 2. Villaviudas I (Palencia). 3. Villaviudas II (Palencia). 4. Espada de Guadalajara. 5. Rodríguez Bauzá II (¿Guadalajara?). 6. Rodríguez Bauzá III (¿Guadalajara?). 7. Puertollano (Ciudad Real). 8. Linares (Jaén). 9. Rincón de Almendricos (Murcia). 10. El Argar 429 (Almería). 11. El Argar 824 (Almería). 12. Montejícar (Granada). 13. Cuevallusa I (Santander). 14. Cuevallusa II (Santander). 15. Cuevallusa III (Santander). 16. Entrambasaguas (Santander). 17. Cabeza Gorda de Totana (Murcia). 18. Fuente Álamo 9 (Almería). 19. Castillejo de Atarfe (Granada). 20. La Herradura (Granada). 21. Setefilla ? (Sevilla). 22. Forcas (Orense). 23. Chapa de oro de Abía de la Obispalía (Cuenca). 24. Cueva de Las Ventanas de Piñar (Granada).

\section{ESTUDIO METALÚRGICO}

En la problemática general de talleres de producción con soluciones funcionales o estéticas comunes, no podemos obviar los resultados analíticos del metal de muchas de estas espadas ya que ayudan a perfilar algunas de las argumentaciones de este trabajo. Hasta la fecha, hay análisis de 10 espadas con arcos dobles (Tabla I) y análisis de otras 12 espadas sin improntas (Tabla II). 
Los análisis de la espada de La Perla han sido realizados por microscopía electrónica de barrido en la Facultad de Ciencias de la Universidad Autónoma de Madrid ${ }^{6}$. Para la obtención de las muestras han bastado unas pequeñas limaduras en la parte superior central de la empuñadura y en la cara posterior del remache central. En total se han llevado a cabo dieciséis análisis, ocho para la hoja y otros ocho para el remache. El cálculo de la media ponderada de los resultados, desechando los análisis de mayor y menor contenido de arsénico, ha dado un cobre arsenicado tanto para la espada como para el pasador cuyas proporciones exactas figuran en la tabla correspondiente.

Las dos fuentes principales de análisis de las espadas españolas son el grupo de Sttutgart (SAM) y el Proyecto de Arqueometalurgia de la Península Ibérica. Hay que añadir un análisis cualitativo recogido en la obra de los Siret para la espada de la sepultura 9 de Fuente Álamo que dio un bronce con cantidades de estaño apreciables aunque sin cuantificar (Siret, 1890: 276, tabla III $)^{7}$ y otro, practicado a la espada de Setefilla en Barcelona con un resultado bastante similar a los del Proyecto de Arqueometalurgia (Aubet et alii, 1983: 62). Los análisis de los distintos laboratorios son coincidentes entre sí en cuanto al tipo de aleación (elementos mayoritarios) y aunque existen pequeñas variaciones en los porcentajes minoritarios, pueden considerarse series comparables en un estudio general ${ }^{8}$. Quizá, señalar que en el caso del arsénico, las cifras son ligeramente menores en los resultados españoles aunque son valores más precisos pues están expresados en números totales y no en genéricos, como ocurre a veces en los análisis publicados en los SAM.

Del conjunto de espadas con marcas analizadas, el mayor porcentaje lo ocupan las espadas de cobre arsenicado, con seis ejemplos: La Perla, Villaviudas I, Rodríguez Bauzá III, Montejícar, Atarfe y Setefilla. Otra espada, la de Linares, es de cobre, la de Guadalajara es de cobre con muy poco arsénico $(1.1 \%)$ y sólo dos son bronces, la espada de El Argar 429 y la de Puertollano. Cuestiones cronológicas aparte, que se tratarán más adelante, estos resultados indican una producción de metal que es independiente de la zona geográfica de los hallazgos, ya que hay cobres arsenicados tanto en la Meseta como en el Sureste. También los pocos bronces hallados se reparten de forma aleatoria con ejemplos como los de El Argar 429, Fuente Álamo 9 y Puertollano, además la espada leonesa de Cea que no lleva marcas. No olvidamos que algunas de estas espadas provienen de colecciones particulares, por lo que la asignación geográfica podría ser en algún caso distinta. Una observación a las espadas que podríamos considerar como las más representativas, ya que cuentan con elementos de metal precioso, bien en la empuñadura bien en los fijadores, indica también producciones dispares en las que al parecer no se tuvo en cuenta el metal de la hoja. Así la espada de Guadalajara con empuñadura de oro es una espada de cobre apenas arsenicado, la espada de Puertollano tachonada con remaches de plata es de bronce y la espada de Montefrío con un pasador de plata es cobre arsenicado. Tampoco existe patrón en el uso de un determinado tipo de aleación dependiendo de la tipología de las espadas realizada por Almagro Gorbea en 1972. En

6 Equipo operado por Dña. Esperanza Salvador. El microscopio es un modelo XL 30 de Philips, con fuente de wolframio, detectores de electrones secundarios y retrodispersados, alcanzando un vacío de $3 \times 10^{-6}$ torr. El análisis químico es por energía dispersiva de rayos X, con detector de Si-Li y analizador DX4i de EDAX.

7 Aparte de estos análisis hay en la bibliografía exámenes analíticos de otras dos espadas con arcos, la espada del Rincón de Almendricos (Ayala et alii, 1989; Ayala, 1991) y de Cabeza Gorda de Totana (Ayala y Tudela, 1993), cuyos resultados no se han incluido en la tabla ya que desafortunadamente no son válidos al haberse producido un error en la sistemática empleada con la confusión de los valores As y Pb (Montero, 1994: 45). Un análisis anterior de la espada del Rincón de Almendricos, por absorción atómica, dio como elemento mayoritario el cobre, con algo de arsénico, hierro y estaño (Ayala y Polo, 1987: 525).

8 Para más información sobre las variaciones de resultados según diferentes laboratorios y técnicas empleadas, véase un trabajo reciente que llega la conclusión de la validez de estudios cruzados siempre que se cuente con patrones de referencia apropiados (Northover y Rychner, 1998). 
las espadas del tipo I, las más anchas, predominan los cobres arsenicados pero es una aleación

TABLA I: ANÁLISIS DE ESPADAS CON IMPRONTAS DE ARCOS DOBLES EN LA EMPUÑADURA.

\begin{tabular}{|c|c|c|c|c|c|c|c|c|c|c|c|c|}
\hline ESPADA & FE & NI & $\mathrm{Cu}$ & $\mathbf{Z N}$ & As & AG & SN & SB & PB & BI & $\mathbf{A U}$ & BIBLIOGRAFÍA \\
\hline La Perla & & & & & & & & & & & & \\
\hline Empuñadura & nd & nd & 95.41 & nd & 4.54 & 0.05 & nd & nd & nd & nd & $\operatorname{tr}$ & Inédito \\
\hline $\begin{array}{l}\text { Remache } \\
\text { Central }\end{array}$ & 0.48 & nd & 96.67 & nd & 2.44 & 0.18 & 0.23 & nd & nd & nd & $\operatorname{tr}$ & Inédito \\
\hline Hoja & 0 & 0 & 97.59 & 0 & 2.4 & $\mathrm{r}$ & 0 & 0 & 0 & $<0.001$ & 0 & $\begin{array}{c}\text { SAM 2,3: } 1968 \\
\text { Anál. } 1007 \text { p. } 10-11\end{array}$ \\
\hline Villaviudas I & 0.023 & nd & 97.51 & 0.16 & 2.27 & 0.006 & nd & 0.005 & nd & nd & - & $\begin{array}{l}\text { Rovira et al.: } 1997 \\
\text { p. } 303 .\end{array}$ \\
\hline $\begin{array}{l}\text { Guadalajara } \\
\text { Hoja }\end{array}$ & 0.110 & nd & 98.73 & nd & 1.140 & 0.004 & $\operatorname{tr}$ & 0.004 & $\operatorname{tr}$ & nd & - & $\begin{array}{l}\text { Rovira et al.: } 1997 \\
\text { p. } 215-216 .\end{array}$ \\
\hline $\begin{array}{l}\text { Empuñadura } \\
\text { de oro }\end{array}$ & & & 0.58 & & & 5.080 & 0.049 & 0.007 & nd & & 94.3 & Idem \\
\hline Pomo de oro & & & 0.44 & & & 3.140 & 0.013 & 0.007 & nd & & 96.4 & Idem \\
\hline $\begin{array}{l}\text { Rodríguez } \\
\text { Bauzá III }\end{array}$ & 0.065 & nd & 97.34 & nd & 1.934 & 0.008 & 0.011 & 0.012 & 0.064 & nd & - & $\begin{array}{c}\text { Rovira et al.: } 1997 \\
\text { p. } 215 .\end{array}$ \\
\hline $\begin{array}{l}\text { Puertollano } \\
\text { Hoja }\end{array}$ & 0.095 & 0.061 & 85.67 & nd & nd & 0.011 & 13.93 & nd & 0.099 & nd & - & $\begin{array}{c}\text { Rovira et al.:1997 } \\
\text { p. } 156 .\end{array}$ \\
\hline $\begin{array}{l}\text { Remache de } \\
\text { Plata }\end{array}$ & 0.107 & 0.209 & 10.96 & nd & nd & 88.21 & 0.531 & nd & nd & nd & 0.200 & Idem \\
\hline Hoja & 0 & 0.078 & 93.8 & 0 & 0 & 0.014 & $\sim 6.1$ & 0 & 0 & 0 & 0 & $\begin{array}{c}\text { SAM, 2,3: } 1968 \\
\text { Anál. } 2267 \text { p. 50-51. }\end{array}$ \\
\hline Linares & 0.074 & 0.034 & 98.50 & nd & 0.982 & 0.005 & 0.008 & 0.013 & nd & nd & - & $\begin{array}{l}\text { Rovira et al. : } 1997 \\
\text { p. } 232 .\end{array}$ \\
\hline Argar 429 & $\operatorname{tr} ?$ & & 92.12 & & & & 7.88 & & & & & Siret: 1890 , p. 275. \\
\hline Montejícar & 0 & $\operatorname{Tr}$ & 97.97 & 0 & 2.0 & 0.01 & 0 & 0 & 0 & 0.018 & 0 & $\begin{array}{c}\text { SAM, 2,3: } 1968 \\
\text { Anál. } 2370 \text { p. } 54-55\end{array}$ \\
\hline Atarfe & 0.063 & 0.039 & 97.31 & nd & 2.16 & 0.007 & 0.008 & 0.014 & nd & nd & - & $\begin{array}{c}\text { Rovira et al.: } 1997 \\
\text { p. } 197 .\end{array}$ \\
\hline Atarfe & 0 & $\operatorname{tr}$ & 97.08 & 0 & 2.8 & 0.066 & 0 & 0 & 0 & 0.05 & 0 & $\begin{array}{c}\text { SAM, 2,3: } 1968 \\
\text { Anál. } 2265 \text { p. 50-51. }\end{array}$ \\
\hline $\begin{array}{l}\text { Setefilla } \\
\text { Empuñadura }\end{array}$ & 0.036 & nd & 99.10 & nd & 0.846 & 0.007 & nd & 0.011 & nd & - & - & $\begin{array}{l}\text { Rovira et al.: } 1997 \\
\text { pp. } 340-341 .\end{array}$ \\
\hline Punta & 0.086 & nd & 97.86 & nd & 2.036 & 0.005 & nd & 0.010 & nd & - & - & Idem \\
\hline Centro de hoja & 0.126 & nd & 98.97 & nd & 1.057 & 0.006 & nd & 0.014 & nd & - & - & Idem \\
\hline
\end{tabular}

nd: no detectado

tr: trazas

— : no buscado

que también se da en espadas más evolucionadas de bordes rectos y paralelos, tipo II, como la de Atarfe. Si comparamos los análisis de espadas sin marcas dobles (Tabla II) vemos también 
que la tónica general es una mayor presencia de espadas de cobre arsenicado, en este caso casi absoluta, ya que de 12 espadas analizadas sólo el estoque de Cea es de bronce.

Obviamente estamos trabajando con los resultados de 22 espadas por lo que las clasificaciones pueden variar en el futuro. Sería especialmente interesante conocer el tipo de aleación de otras espadas de hoja larga, como la de la tumba 824 de El Argar para confirmar el uso del bronce en la fabricación de espadas de los poblados más típicos de lo argárico como Fuente Álamo o El Argar, aunque posiblemente predomine la diversidad ya que la espada corta de El Argar 994 ha dado un cobre arsenicado, que es un tipo de metal ampliamente utilizado en toda la metalistería argárica (Montero, 1994).

Igualmente revelador sería contar con análisis metalográficos. Por preservar al máximo la integridad de la espada de la Perla, que se encuentra en perfecto estado de conservación, no se han realizado metalografías para ver los tratamientos mecánicos posteriores al vaciado del molde de la pieza. Es seguro que todas las espadas eran fundidas en moldes, pues aunque no conocemos hallazgos en España anteriores al Bronce Final avanzado ${ }^{9}$, existe un importante número de moldes en la Península Ibérica, ya desde el Calcolítico, utilizado en la fundición de útiles de pequeño y mediano tamaño y de tipología diversa, especialmente punzones y hachas planas (Rovira Hortalà, 1988: 244, tabl. II; Gómez Ramos, 1999: 45-59 y 78-86). Las secciones de las hojas de estas espadas son lo suficientemente planas como para no necesitar moldes bivalvos ya que su fabricación terminaba con el martilleado o forjado en frío para aumentar la dureza del metal pero sobre todo, para darles la forma final. Los análisis metalográficos de dos puñales argáricos de cobre (Montero, 1994: 386-387) apoyan esta idea. Las fotografías demuestran prácticas de forjado en frío en el filo de la hoja de uno de los puñales pero también granos de recocido en el otro ejemplar, y que se integra dentro del proceso de experimentación propio de los metalúrgicos antiguos.

Desgraciadamente hay pocos análisis metalográficos de espadas de la Edad del Bronce, por lo que hasta que no se realicen metalografías no podrán establecerse conclusiones más asentadas de las técnicas de manufactura. Las referencias más próximas a las espadas del Bronce Medio nos llevan a los estudios realizados por autores extranjeros, en especial, las espadas bretonas de Carnoët (Briard y Mohen, 1974). Según los análisis químicos practicados a la espada número 2 de este túmulo, tanto la hoja como uno de los remaches aportan una composición de cobre arsenicado, muy similar en porcentajes, sobre todo en el caso de roblón, a la espada de La Perla. Las fotografías indican claramente que esta espada sufrió una fase previa de recocido y un tratamiento ulterior de forjado ${ }^{10} \mathrm{y}$ donde destaca un fuerte enriquecimiento superficial de arsénico que dio a las armas de Carnoët un brillo especial, de aspecto «plateado» ya desde el momento mismo de su fabricación y que al parecer también tiene la espada de Cuevallusa I (Almagro Gorbea, 1976: 460). Aunque se trata de un fenómeno peculiar y muy escaso, está documentado también en otras piezas de momentos cronológicos y culturales dispares. Varias espadas de cobre arsenicado del Mediterráneo oriental con una cronología de finales del Bronce Medio, también con tratamientos de forjado y reco-

9 Son sumamente escasos, pero sí existen moldes univalvos de piedra y arcilla cocida para la fundición de espadas en el Bronce Medio como por ejemplo, en el yacimiento francés de Fort-Harrouard (Mohen y Bailloud, 1987: 130-131) o en Italia con el hallazgo de un molde para fundir una espada de remaches en Castioni dei Marchesi (Peroni, 1970: 1415, tafel 2). Son más abundantes a finales del Bronce, algunos de ellos aparecidos en el ámbito español como son los fragmentos de moldes para espadas del Bronce Final de los yacimientos de Regal de Pídola, Huesca (Barril et alii, 1982: 370, fig. 1.1), Peña Negra I, Alicante (Gónzalez Prats, 1990: 22, lám, I, y 347-348, figs. 1.1 y 1.2) o el espectacular molde bivalvo de Ronda (Amo, 1983).

10 Los tramientos mecánicos de recocido y forjado fueron algo genérico en la fabricación de espadas no sólo durante el Bronce Medio. Un buen ejemplo, lo representan las espadas del Bronce Final británico que muestran estructuras características con maclas de recocido y de forjado en frío, señales de los trabajos alternos practicados (Bridgford, 1998: 209 y 213, figs. 1 y 4) así como también algunas espadas del depósito de la Ría de Huelva (Rovira, 1995). 
cido, presentan este tipo de segregaciones (Shalev: 1988). Enriquecimiento que sin embargo, todavía no ha podido ser explicado de forma satisfactoria y aunque se han dado diversas interpretaciones (Stanley, 1973), parece que no está vinculado necesariamente con porcentajes

TABLA II: ANÁLISIS DE ESPADAS SIN MARCAS EN LA EMPUÑADURA.

\begin{tabular}{|c|c|c|c|c|c|c|c|c|c|c|c|c|}
\hline ESPADA & $\mathbf{F E}$ & NI & $\mathrm{Cu}$ & $Z_{N}$ & As & AG & $\mathrm{SN}_{\mathrm{N}}$ & SB & Рв & BI & $\mathbf{A U}$ & BIBLIOGRAFÍA \\
\hline Fontaneda & 0.068 & nd & 98.42 & 0.17 & 1.18 & 0.016 & nd & 0.042 & nd & nd & - & $\begin{array}{l}\text { Rovira et al. } 1997 \\
\text { p. } 300 .\end{array}$ \\
\hline $\begin{array}{l}\text { Santa Olalla } \\
\text { Análisis A }\end{array}$ & 0.065 & 0.147 & 98.24 & nd & 1.329 & 0.016 & nd & 0.101 & nd & - & - & $\begin{array}{l}\text { Rovira et al. } 1997 \\
\text { p. } 127 .\end{array}$ \\
\hline Análisis B & 0.065 & 0.188 & 98.09 & nd & 1.506 & 0.023 & nd & 0.128 & nd & - & - & Idem \\
\hline Sabero & 0.112 & nd & 98.83 & nd & 1.023 & 0.006 & nd & 0.007 & nd & nd & - & $\begin{array}{l}\text { Rovira et al. } 1997 \\
\text { p. } 241 .\end{array}$ \\
\hline Cea & 0.065 & 0.025 & 87.40 & 0.12 & 0.07 & 0.034 & 11.19 & 0.853 & 0.102 & nd & - & $\begin{array}{l}\text { Rovira et al. } 1997 \\
\text { p. } 238 .\end{array}$ \\
\hline Fuente Tójar & 0.07 & nd & 96.56 & nd & 2.07 & $\operatorname{tr}$ & 0.01 & 0.005 & nd & nd & - & $\begin{array}{l}\text { Rovira et al. } 1997 \\
\text { p. } 165 .\end{array}$ \\
\hline Fuente Tójar & 0 & 0 & 96.1 & 0 & 3.9 & 0 & 0 & 0 & 0 & 0 & 0 & $\begin{array}{c}\text { SAM, 2,3: } 1968 \\
\text { Anál. } 2266 \text { p. 50-51. }\end{array}$ \\
\hline Trebujena & 0.133 & nd & 96.88 & nd & 2.976 & 0.006 & nd & 0.008 & nd & - & - & $\begin{array}{l}\text { Rovira et al: } 1997 \\
\text { p. } 141 .\end{array}$ \\
\hline Argar 994 & 0.01 & tr & 97.81 & 0.27 & 1.56 & 0.001 & $\operatorname{tr}$ & 0.006 & nd & nd & - & $\begin{array}{l}\text { Rovira et al. } 1997 \\
\text { p. } 46 .\end{array}$ \\
\hline $\begin{array}{l}\text { El Zabalí } \\
N^{\circ} .1935\end{array}$ & 0 & 0 & 97.68 & 0 & 2.3 & $<0.01$ & 0 & $\operatorname{tr}$ & 0 & 0.008 & 0 & $\begin{array}{c}\text { SAM, 2,4: } 1974 \\
\text { Anál. } 12312 \text { p } 78-79\end{array}$ \\
\hline $\begin{array}{l}\text { El Zabalí } \\
N^{\circ} .1936\end{array}$ & 0 & 0 & 98.56 & 0 & 1.3 & 0.1 & $\operatorname{tr}$ & 0.04 & 0 & $\operatorname{tr}$ & 0 & $\begin{array}{c}\text { SAM, 2,4: } 1974 \\
\text { Anál. } 12313 \text { p 78-79 }\end{array}$ \\
\hline $\begin{array}{l}\text { El Zabalí } \\
N^{\circ} .1937 \mathbf{a}\end{array}$ & 0 & 0 & 98.47 & 0 & 1.5 & $<0.01$ & $\operatorname{tr}$ & $\operatorname{tr}$ & 0 & 0.013 & 0 & $\begin{array}{c}\text { SAM, 2,4: } 1974 \\
\text { Anál. } 12314 \text { p } 78-79\end{array}$ \\
\hline $\begin{array}{l}\text { Cortes de } \\
\text { Baza }\end{array}$ & $\operatorname{tr}$ & 0 & 98.24 & 0 & 1.65 & 0.06 & $<0.01$ & 0.02 & $\operatorname{tr}$ & 0.016 & 0 & $\begin{array}{c}\text { SAM, 2,4: } 1974 \\
\text { Anál. } 16507 \text { p. 208-209. }\end{array}$ \\
\hline Montefrío & 0 & 0 & 97.23 & 0 & 2.75 & 0.018 & 0 & 0 & 0 & 0 & 0 & $\begin{array}{c}\text { SAM, 2,3: } 1968 \\
\text { Anál. 2371 p 54-55 }\end{array}$ \\
\hline
\end{tabular}

nd: no detectado

tr: trazas

— : no buscado

altos de arsénico ( $c f r$. tabla 2 de Shalev, 1988). Pero independientemente de su origen último, este hecho resulta de gran interés ya que sin duda acentuó el valor simbólico de algunas de estas espadas, tema que retomaremos más adelante, pudiendo marcar incluso, una nota más en la connotación mágica de la metalurgia antigua y de los artesanos implicados en su fabricación, en un fenómeno que sin embargo, pudo ser totalmente fortuito.

Ya hemos llamado la atención sobre la diferencia de arsénico existente entre la hoja y el remache de la espada de La Perla. Con respecto a los remaches existen varios análisis espectrográficos practicados a puñales y alabardas argáricas donde también se observa esa dicotomía aunque en lo aleatorio de esta práctica incide el hecho de que otros puñales argáricos presentaban menos contenido de arsénico que sus respectivos remaches, como los ejemplos de El Barranquete, Almería o los granadinos de El Guadix, Terrera del Reloj, Cuesta del Negro o Puerto Lope (Montero, 1992: 267, 310, 318, 321 y 333) y que está indicando la fa- 
bricación, en coladas separadas, de remaches por un lado, y hojas por otro (Montero, 1994: 257). Sin embargo, análisis metalográficos sólo hay uno. En concreto, la alabarda de Herrerías, cuya hoja ofrece una tasa de $5.39 \%$ de arsénico y $0.94 \%$ para el remache. Según la metalografía se observa también una microestructura fibrosa de un metal forjado en frío (Montero, 1992: 417; 1994: 364) consecuencia directa de la deformación producida al remachar el pasador y fijar así la empuñadura y la hoja.

A tenor de los resultados analíticos, que reflejan que el número mayor de espadas corresponde a cobres arsenicados, no puede dejarse de lado un breve comentario. Vimos anteriormente, como espadas y puñales sufrieron tratamientos de endurecimiento, principalmente en los filos de las hojas, mediante forja en frío. También la presencia de arsénico en la liga aportaba una dureza extra mayor que la que poseen los cobres más puros. Mientras que un cobre sin arsénico sacado de la colada tiene una dureza 79 en la escala Brinell, trabajado en frío llega hasta 132, cifra que puede subir a 177 con sólo tener un $1.04 \%$ de contenido de arsénico (Healy, 1993: 262). De hecho, el cobre trabajado en frío, con un porcentaje de hasta un $8 \%$ de arsénico, que es la cantidad máxima que permite la solubilidad sólida entre ambos metales en la aleación, tiene una dureza, no sólo muy superior a la del cobre no arsenicado, sino que incluso es comparable a la de un bronce con las mismas titulaciones de estaño (véase Tylecote, 1976: 8, fig. 2). Pero aparte del contenido de arsénico el resultado dependía mucho de las labores de taller que se practicaran sobre el objeto. La forja en frío se presenta como el proceso mecánico más apto para endurecer el cobre arsenicado, con resultados mucho más satisfactorios que los métodos de calentamiento o recocido. Sin embargo, los pocos exámenes metalográficos de espadas indican que los sistemas de trabajo en caliente fueron una práctica común, lo que significaba de hecho una pérdida importante de la dureza que podría haberse obtenido sólo forjando la pieza (Budd: 1991: 96 y ss). Así, aunque la mayoría de las espadas analizadas en este trabajo, se encuentran en el rango óptimo para obtener la mayor dureza posible, que es una composición del 2 al $6 \%$ de arsénico, puede que el resultado variara en función de los tratamientos practicados posteriores al moldeo. Estamos aceptando sin demasiada crítica, que los artesanos de la Edad del Bronce conocían todas estas propiedades teóricas después de numerosos ensayos prácticos. Sin embargo, no está en absoluto claro que el arsénico fuera empleado intencionadamente en la fabricación de útiles durante la Prehistoria, aunque sí fue un hecho derivado, quizá del empleo de menas de arseniatos de cobre, lo que pudo beneficiar al objeto final si se siguieron los tratamientos mecánicos adecuados.

\section{CONSIDERACIONES FINALES}

Durante el Bronce Antiguo y Medio se están fabricando una serie de armas, tanto en el norte peninsular como en la Bretaña francesa, que como evoluciones locales de prototipos campaniformes conforman un panorama sumamente complejo. Aunque existen particularidades propias de cada zona, también van a compartir características formales, lo que complica la posible autoctonía de muchas de estas armas y en las que están implicadas por ejemplo, las espadas de Cuevallusa o Sabero y distintas espadas atlánticas.

Si nos ceñimos a espadas con marcas dobles, parece claro que las espadas santanderinas de Cuevallusa, en concreto Cuevallausa I, según algunos rasgos tipológicos, pertenece al modelo peninsular más antiguo que presentan este tipo de marcas. El resto de espiga y la decoración multiestriada de la hoja la acerca a tipos de espadas de lengüeta simple, presentes entre otros sitios, en los Túmulos Armoricanos del Bronce Antiguo francés. De hecho, existen armas con espigas, remaches y decoración acanalada muy similares a esta espada, como son las espadas de cobre arsenicado de los túmulos de Carnoët en el Finisterre francés (Briard y Mohen, 
1974; Briard, 1984: 86-87, fig. 53) de una cronología precisa en el Bronce Antiguo, que añade interrogantes al posible origen de fabricación de las espadas de ambas zonas.

Sin embargo, las espadas armoricanas de Carnoët con estrechamiento progresivo de la hoja, semejantes a otros ejemplares en los túmulos de Trémel o Bourbriac (Briard, 1969) las aproxima más a otras espadas o puñales peninsulares del Bronce antiguo, entre otros, el de Sabero (León) o el de Trebujena (Cádiz) también con empuñaduras aseguradas mediante espigas y remaches y por lo tanto, distintas ya de los precedentes campaniformes que no cuentan aún con remaches. Las piezas españolas, especialmente la leonesa de Sabero (Delibes et alii, 1982) encuentra concordancias formales con los puñales de los túmulos de Kerhuella (Briard, 1984: 149, fig. 90). Son hojas prácticamente de idéntica longitud, unos $30 \mathrm{~cm}$., de forma similar y con decoración estriada de tres bandas aunque la diferencia estriba en el enmangue pues aunque ambos llevan remaches, en el caso galo no presenta lengüeta atrofiada (está fragmentado) y sí una escotadura en forma de arco muy común en otros puñales de este momento y posteriores ya en el Bronce Medio, como son los aparecidos en los túmulos armoricanos de Kervellerin en Clérguer o Kervolant en Saint-Frégant (Briard, 1984: 85, fig. 51).

La forma de la hoja y la marca de arco duplicado de Cuevallusa I tiene como único paralelo inmediato una espada del Bronce Antiguo hallada en Aquitania que es la espada de Cissac y que no pasó por alto Almagro Gorbea (1972 y 1976). Se trata de una espada de hoja ancha que presenta una huella doble incompleta (Coffyn, 1976: 533-534 y 540, fig. 1, nº 9 , lám. 1). Posiblemente arsenicada y con remaches de plata, que el autor paraleliza con las armas argáricas y a su vez, con las espadas de Carnöet. Sin embargo, la hoja de Cissac, lleva una aparatosa decoración central muy distinta a cualquier otra espada española, lo que podría indicar la fabricación independiente y originaria de la espada de Cuevallusa I más que una posible importación. Curiosamente la doble señal de la espada de Cissac, no va a tener correspondencia ni en las otras espadas del Bronce Antiguo francés, ni tampoco durante el Bronce Medio en donde vemos que las armas bretonas de los tipos Tréboul o Saint-Brandan (Briard, 1965: 89-90, figs. 26-27) repetirán hasta la saciedad el modelo europeo de un solo arco, de ahí el carácter único de la marca doble en la armamentística peninsular donde se va a utilizar como elemento característico, no en algunas espadas, sino posiblemente en todas ellas. En la propia Aquitania durante el Bronce Medio las espadas presentan también una única escotadura central extendida hacia los bordes de la empuñadura en dos líneas más o menos cerradas como puede observarse en las armas de tipo Cheylounet (Briard, 1965: 101, fig. $33, n^{\circ} .5$ y 6) y por lo tanto, ajeno al modelo del doble arco peninsular.

De momento parece indudable que existieron relaciones, cuando no un trasiego de metales, que tuvo como epicentro, en un sentido amplio, el golfo de Vizcaya. Las pruebas actuales indican que la peculiaridad del doble arco pudo haber surgido, posiblemente ya durante el Bronce Antiguo en el norte de la Península Ibérica, si aceptamos la cronología de finales del Bronce Antiguo para la espada de Cuevallusa I por sus paralelos con Cissac como defendiera también Almagro Gorbea (1976: 471), y extenderse desde allí hacia el sur para llegar a otras áreas peninsulares ya durante el Bronce Medio. Es una hipótesis arriesgada, pero está claro que los broncistas del norte hispano se decantaron por dar un aspecto distinto a sus espadas poniendo empuñaduras de doble arco y estrechando la hoja de forma más brusca que otros modelos foráneos. Quizá como genio particular para distinguir desde el primer instante sus armas más emblemáticas de otras similares que en ese tiempo se estaban fabricando en el área atlántica. El precisar los posibles orígenes de fabricación de las espadas «argáricas» halladas lejos del área nuclear de esta cultura es mucho más difícil. Existe una presencia generalizada de armas muy similares por toda la geografía española desde el Bronce Antiguo, como ejemplifican la espada gaditana de Trebujena con paralelos formales con la leonesa de Sabero. La espada santanderina de Entrambasaguas es prácticamente la misma pieza que la espada murciana de La Herradura, ya que incluso comparten una desviación respecto al eje 
longitudinal, y donde las ligeras variaciones del extremo proximal, indican el empleo de moldes distintos y coladas independientes, pero siguiendo esquemas morfológicos casi idénticos. La correspondencia morfológica se da también entre la empuñadura de oro de la espada de Guadalajara y la impronta de la espada Argar 824, ambas con marcas de herradura y ambas, bordeadas curiosamente de líneas de puntos, siendo difícil sortear sugestivos paralelos, en este caso, con las decoraciones cerámicas de boquique. La espada de La Perla representa a su vez una excepcionalidad dentro la metalurgia madrileña, encuadrada en un panorama de lo metálico bastante uniforme (Gómez Ramos, 2000). Sin embargo, esa distribución más o menos generalizada, podría estar señalando fabricaciones locales en cada zona más que uno o dos talleres de producción enclavados en una región concreta, como por ejemplo, el Sureste, sobre todo, como bien señalara Almagro Gorbea en su estudio de la espada de Entrambasaguas, porque se conoce la evolución de las espadas en el norte y área atlántica pero no en El Argar o en Fuente Álamo, donde parecen surgir espadas ya totalmente formadas, casi repentinamente. El predominio cultural de lo argárico como foco progresista del Bronce peninsular queda en entredicho ya que las influencias externas tanto en el campo morfométrico como en los tipos de aleación empleados, no vendrían sólo de ambientes extrapeninsulares como siempre se ha defendido, sino que habría que valorar también el influjo de regiones septentrionales dentro de la misma Península Ibérica.

Relacionado con lo expuesto hasta ahora, uno de los temas que más se prestan a debate es el de la cronología concreta de las espadas. La inmensa mayoría carece de contexto asociado que permita fijar cronologías absolutas, por lo que la única posibilidad es acercarnos a su cronología relativa. Almagro Gorbea (1972) clasificaba todas las espadas halladas dentro del Bronce Medio, en un arco amplio que iba aproximadamente del 1500 al 900 a. C. siendo las más antiguas las espadas de los tipos I y II mientras que ejemplares como el de Forcas entraría de lleno en el Bronce Final. La cronología relativa para la espada de La Perla quedaría pasada la mitad del segundo milenio agrupada con otras espadas del tipo Ic como Villaviudas I o Santa Olalla de Bureba.

Aunque posiblemente sea complicado establecer una seriación cronológica para las espadas basándonos únicamente en las variedades morfológicas, parece que el arranque, si aceptamos como más antigua la espada de Cuevallusa I, se situaría a finales del Bronce Antiguo. Se trata de una fecha relativa dada por paralelos tipológicos con otras armas bretonas como las de Carnoët o Cissac, fechadas por los investigadores franceses en el Bronce Antiguo, mediante las fechas radiocarbónicas aportadas por la primera serie de los túmulos armoricanos y que van entre el 1900-1800 y el 1600 a.C. (Briard, 1976: 564). Los rasgos arcaizantes de esta espada y de los ejemplares de Trebujena o Sabero, no repetidos más en la serie de espadas peninsulares, indicarían una evolución, lineal o no, desde prototipos del grupo I.

Igual de difícil es aquilatar la cronología de las espadas propiamente argáricas, adscritas genéricamente a la fase B de esta cultura, a pesar de que algunas de ellas se asocian a otros elementos arqueológicos y aparecen en yacimientos con fechaciones radiocarbónicas. En concreto, me refiero a Fuente Álamo, Rincón de Almendricos y Setefilla, si es que aceptamos incluir esta última en la serie de espadas marcadas. Para Fuente Álamo, las dataciones obtenidas en excavaciones recientes, oscilan entre el 2020 90 (? 1372) para el horizonte I y el 1210 \pm 90 a.C. (? 644) para el horizonte V, ya en el Bronce Tardío (Schubart y Arteaga, 1986: 292). En una revisión de las fechas más fiables el lapso temporal iría del 2282 al 1523 cal AC, en fechas máximas calibradas (Maya y Mestres, 1996: 263-264). Es una cronología muy dilatada, independientemente de la clasificación convencional aportada por B. Blance, en la habría que incluir la espada 9 de Fuente Álamo, que proviene de las excavaciones antiguas de Siret y para la que no existen fechas absolutas asociadas. La fecha dada a las cuentas de vidrio encontradas junto a esta espada es mediados del siglo XV a.C. (Almagro Gorbea, 1972: 75) con una perduración hasta momentos tardíos (Lull, 1983: 212). En el caso de Rin- 
cón de Almendricos existe una fecha radiocarbónica que ha dado 1730 \pm 100 a.C. (UGRA 146) (Ayala, 1991: 132), que sin embargo, aparte de que una única fecha es siempre insuficiente, no pertenece a la cista donde apareció la espada por lo que tampoco determina con exactitud la cronología del hallazgo metálico. La asociación de esta espada con una alabarda tipo Argar A y una olla bicónica tipo 6 de Siret, indican para esta investigadora una cronología antigua que debe situarse antes del 1500 a.C. No obstante, en la revisión estadística de los elementos típicos de lo argárico, se ve que tanto la alabarda como las cerámicas de este tipo parecen no servir por sí solas como fósiles claros de valor cronológico (Lull, 1983: 152

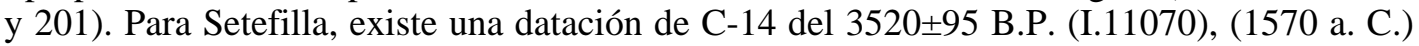
procedente del momento final del estrato XIV, donde apareció la espada, que los autores incluyen en el Bronce Pleno paralelizable al Argar B (Aubet et alii, 1983: 48 y 136), con fechas calibradas que irían del 2129 al 1612 cal AC (Maya y Mestres, 1996: 264), transición Argar A y B, en la terminología al uso. Sin embargo, el estudio tipológico de esta espada y de los materiales metálicos asociados a ella, avalaría para Aubet et alii (1983: 62 y ss), una cronología alta, lo que retrotraería aún más la cronología de la serie. La cerámica de esta sepultura y los vasos de tipo argaroide del arenero de La Perla, muestran una serie de cerámicas, producciones más o menos particulares de formas argáricas, que se integran a grandes rasgos en el Bronce Medio apareciendo ampliamente repartidas por distintas áreas peninsulares (La Mancha, Levante, Suroeste, etc.) y por lo tanto, con solapamientos cronológicos evidentes. El resto de espadas del Bronce carece de dataciones absolutas así como de contexto o elementos arqueológicos asociados. Las espadas argáricas del Sureste, en espera que la investigación española termine por definir la secuencia cultural y temporal de lo argárico ${ }^{11}$, podrían ser coetáneas a otras espadas de la zona centro peninsular o incluso más recientes.

Tal vez pueda obtenerse más información de la lectura de los análisis metalúrgicos. Sorprende que la inmensa mayoría de las espadas sean de cobre arsenicado, algo que a priori, podría indicar un ambiente arcaizante para espadas del Bronce Medio. La ecuación «metal bronce igual cronología más reciente» sólo se cumple en las espadas de Fuente Álamo 9, Argar 429, Puertollano y Cea, lo que apoyaría la evolución más moderna dada por Almagro Gorbea (1972) para las espadas del grupo IIa. En la afirmación de una cronología anterior para las otras espadas de cobre cabe preguntarse sí el uso del cobre era deliberado, venía condicionado por el aprovisionamiento de las fuentes minerales o sí era fruto de un desconocimiento de la aleación cobre y estaño en el norte y centro peninsular en el momento de fabricación de estas espadas. Las evidencias arqueológicas indican que la aleación de bronce era conocida, esporádicamente, ya durante el Calcolítico en Cataluña (Bauma del Serrat) y Galicia (Guidoiro Areoso) y practicada desde finales del Bronce Antiguo en el tercio norte peninsular como ejemplifican los hallazgos navarros de Monte Aguilar en las Bárdenas Reales, entre el $1560 \pm 20$ AC (GrN-19671) (Rovira et alii, 1998: 156). Poco tiempo después, a mediados del II milenio era ampliamente utilizada también en el centro español pues existen datos de obtención de bronces en distintos yacimientos, algunos de ellos en las regiones de Guadalajara y Madrid (Gómez Ramos, 1999: 98, fig. 24). La expansión de la metalurgia del bronce desde el norte hacia el sur, llegando tardíamente al Sureste (Fernández Miranda et alii, 1995: 67) no se hizo desde luego, a través de la fabricación de espadas, para las que se utilizaron minerales de cobre y arsénico, quizá como perduración de tradiciones calcolíticas y campaniformes anteriores. La derivación tipológica planteada por Almagro Gorbea desde los modelos santanderinos a los argáricos pasando por las espadas meseteñas, no fue pareja, por lo tanto, a la otra expansión desde el norte al sur peninsular que fue la del metal de bronce.

11 En el futuro quizá haya que modificar los esquemas teóricos aportados por la cronología relativa del Bronce peninsular y reconciliarlos con cronologías absolutas, según se desprende de las fechaciones calibradas presentadas por Castro et alii, 1996. 
Esta paradoja, ya que serviría como discriminante cronológico haberse encontrado más espadas de bronce en el Norte y en la Meseta y no sólo en el Sureste, en un momento en el que se está dando también la circulación de la aleación de bronce, nos lleva a la posible intencionalidad y por lo tanto, funcionalidad de estas espadas. Un interés suscitado por casi todos los investigadores que han estudiado las espadas atañe al hipotético carácter simbólico de algunas de estas armas y del que ya hemos apuntado algo al hablar del aspecto argentífero de las armas bretonas de Carnoët. Entre los argumentos esgrimidos el de mayor peso es sin duda, el empleo de metales preciosos, bien en las empuñaduras bien en los remaches. En el caso de España los bronces o cobres combinados con metal de oro o plata, lo representan la espada de Guadalajara, quizá también las chapas áureas de Abía de la Obispalía y las hojas de Puertollano y Montefrío, éstas últimas tachonadas con pasadores de plata. Como vimos anteriormente, posiblemente las espadas de Cuevallusa también deban incluirse en este grupo. El número original debió ser sin embargo, mucho mayor. Así por ejemplo, entre los objetos hallados en la Bastida de Totana, Murcia, había alguna espada con puño de oro actualmente en paradero desconocido (Inchaurrandieta, 1869: 346) y en la sepultura número 7 de Fuente Álamo apareció: «una especie de vasito de plata que sirvió sin duda, de pomo de algún mango» (Siret, 1890: 259). Aunque según la lámina correspondiente, la número 65, se trata de una pieza de pequeño tamaño, morfológicamente es prácticamente igual al arriaz hemiesférico de la espada de Guadalajara, y cuyos restos gráficos aparecen en varias estelas alentejanas como Assento, Santa Vitoria o Pedrerinha (Almagro Gorbea, 1973: 68, fig. 6; Chernokian, 1988: 45, fig. 9, nº 1 y 197-200, fig. 66). Espadas, pero también puñales pudieron contar con empuñaduras que tenían mangos de cuerpo y cabo similares ${ }^{12}$, muchos de ellos de metal precioso y que vendrían a completar algunos ejemplos de pasadores sueltos de plata y puñales con remaches de este metal localizados en distintos yacimientos, principalmente del área argárica (Harrison, 1983; Montero et alii, 1995: 99).

Si las empuñaduras de metal precioso fueron algo excepcional o no, es difícil saberlo ya que se conservan muy pocas. En otras áreas culturales se han encontrado espadas ornadas con mangos de oro cuyos ejemplos más espectaculares se centran durante el Bronce Medio Egeo. Destacan entre otros ítems, la soberbia empuñadura de oro con dos cabezas de leones que con las fauces abiertas apresan la hoja de bronce y conforman un arco, aparecida en una tumba del círculo B de Micenas (Gimbutas, 1965: pl. 8b, $\mathrm{n}^{\circ} .2$ ), las espadas cretenses con chapeados de oro provenientes de Mallia, una de ellas con fragmentos del armazón de madera, otra de Egina con el nervio láminado en oro o la de Staphylos, con puños forrados en oro (Kilian Dirlmeier, 1993: 15, 18-19 y 35; tafeln 3, 6-8). Todas ellas manifiestan un carácter principesco e inciden más en lo prestigioso que en lo meramente combativo, multiplicando ampliamente la información dada por Homero que refería sólo espadas guarnecidas con clavos de plata (La Ilíada, cantos III, 360 y XXIII, 807, Biblioteca Literaria de Akal. Madrid, edición de 1998).

Además de este argumento podrían señalarse otros. El «desprecio» al uso del bronce en la mayoría de las espadas podría indicar que preocupaba poco la resistencia física del metal, importante en unas armas destinadas a priori, no sólo a pinchar, sino también a dar mandobles o cortar a tajo. Las espadas cuyos análisis han dado bronce son principalmente estoques, muy prácticos para herir con la punta, lo que podría indicar más una cuestión cronológica a la hora de utilizar distintos metales si bien los estoques de Setefilla y Fontaneda son cobres arsenicados. Ya señalamos en el apartado del estudio metalúrgico que el arsénico aportaba una dureza superior a la del cobre sin arsénico y que algunas roturas en el filo de la espada de La Perla, visibles ya en la fotografía que presentó Pérez de Barradas en 1936, avalarían su

12 Sería conveniente revisar algunas piezas europeas, clasificadas genéricamente como conteras, porque su sección circular parece indicar más bien pomos de armas de pequeño tamaño que conteras propiamente dichas. 
uso práctico. No obstante, el bronce rico en estaño se presenta como un metal mucho más efectivo que el cobre arsenicado, cuya dureza depende mucho de los tratamientos mecánicos posteriores al moldeo. La espada de Guadalajara, que por su empuñadura de oro se puede considerar como la más emblemática de la serie, es prácticamente sólo de cobre, por lo que podría clasificarse perfectamente como objeto de prestigio. En este sentido, también hay un hecho que llama la atención y es la ausencia de nervio central en las espadas peninsulares anteriores al Bronce Final. El arco simple enmarcaba en casi todas las armas europeas coetáneas, el comienzo de un robusto nervio central que aparte del efecto decorativo, engrosaba las hojas metálicas dándoles mayor eficacia y resistencia. Aunque en la Península este recurso no era desconocido, y se aplicó profusamente en puñales y alabardas (hachas de combate) de la misma época ${ }^{13}$, no ocurrió lo mismo con las espadas españolas, que hasta el Bronce Final son siempre de hoja plana ${ }^{14}$, argumentos que bien pudieran subrayar un carácter ceremonial de las espadas. El privilegio de su posesión garantizaba la autoridad para su portador, y por lo tanto, como símbolo de rango se reservaría sólo para ocasiones especiales, entre ellas, por supuesto, la ocasión funeraria que es donde aparecen de forma mayoritaria.

Pero al margen de lucubraciones, pues muchas de estas ideas son apuntes que deberán desarrollarse ampliamente, lo cierto es que las pruebas actuales muestran sin ambages que los artífices peninsulares eligieron un modelo de enmangar espadas que se mantendrá prácticamente invariable durante siglos, impermeable a influencias externas y que no va a tener su correspondencia en el resto de Europa. Las espadas clásicas del Bronce Final perderán la particularidad del doble arco. Precisamente en la espada de Forcas de hoja larga en forma de lengua de carpa y con arista central, los broncistas optaron por cambiarle la forma primera de la empuñadura —en doble arco — por una en arco simple, más acorde con la moda imperante en esos momentos. De cualquier modo, esperamos que hallazgos arqueológicos venideros, así como observaciones atentas, con la utilización de medios potentes de examen, deparen en el futuro nuevas sorpresas que amplíen el número de estas espadas y ayuden a perfilar el panorama presentado.

\section{PABLO Gómez RAMOS}

Becario Postdoctoral de la Comunidad de Madrid. Facultad de Filosofía y Letras. Dpto. Prehistoria y Arqueología. Universidad Autónoma. 28049 Madrid (España).

\section{BIBLIOGRAFÍA}

Almagro Gorbea, M. (1972): «La espada de Guadalajara y sus paralelos peninsulares», Trabajos de Prehistoria, $\mathrm{n}^{\circ}$. 29: 55-82.

Almagro Gorbea, M. (1974): «Orfebrería del Bronce Final en la Península Ibérica. El tesoro de Abía de la Obispalía, la orfebrería tipo Villena y los cuencos de Axtroki», Trabajos de Prehistoria, nº. $^{\circ}$ 31: 39-100.

13 Sin deseo de ser exhaustivo pueden verse algunos ejemplos, en puñales argáricos (Siret: 1890, passim) y en albardas tipo El Argar (Siret, 1890; Schubart, 1973: 249 y ss., figs. 1 a la 6), tipo Montejícar (Schubart, 1973: 257, fig. 8) o tipo Carrapatas (Schubart, 1973: 255, fig. 7; Sanches, 1995: 30), una de éstas aparecida en el valle del Manzanares (Blas Cortina, 1981).

14 Existen varios ejemplares con filos rebajados e incluso con una fina arista central (Castelo Bom, Montejícar, Forcas...) y aunque alguna espada como la de Montefrío, con un remache central de plata, según algunos dibujos parece tener una nervadura central (Siret, 1913: 381, n. ${ }^{\circ}$ 7, fig. 150) se trata de filos rebajados muy amplios y que no arrancan desde el comienzo de la hoja, lo que las distingue claramente de los puñales y alabardas peninsulares y de otras espadas extrapeninsulares con nervios más marcados. 
Almagro GorbeA, M. (1976): «La espada de Entrambasaguas. Aportación a la secuencia de las espadas del Bronce en el norte de la Península Ibérica», XL Aniversario del Centro de Estudios Montañeses. Tomo III. Institución Cultural de Cantabria, Santander: 455-477.

Aмо, M. del (1983): «Un molde para la fabricación de espadas del Bronce Final hallado en Ronda». En: Homenaje al Prof. Martín Almagro Basch. Tomo II. Ministerio de Cultura. Madrid: 81-94.

Aubet, M. ${ }^{a}$ E. y SeRnA, M. ${ }^{a}$ R. (1981): «Una sepultura de la Edad del Bronce en Setefilla (Sevi1la)», Trabajos de Prehistoria, vol. 38: 225-256.

Aubet, M. ${ }^{a}$ E., Serna, M. ${ }^{a}$ R., Escacena, J. L. y Ruiz Delgado, M. (1983): La Mesa de Setefilla. Lora del Río (Sevilla). Campaña de 1979. Excavaciones Arqueológicas en España, 122. Madrid.

AyAla, M. ${ }^{a}$ M. (1991): El poblamiento argárico en Lorca. Estado de la cuestión. Murcia.

AyAlA, M. y POLO, J. L. (1987): «Dos yacimientos argáricos: el Rincón de Almendricos, el Cerro de las Viñas. Lorca (Murcia)». En el II Convegno di Studi. Actas de un millennio di relazioni fra la Sardegna e i Paesi del Mediterraneo, 1986. Cagliari: 519-531.

Ayala, M. ${ }^{a}$ M. y Tudela, M. ${ }^{a}$ L. (1993): «La espada del poblado argárico «La Cabeza Gorda o Cabezo de la Cruz», Totana (Murcia)», Verdolay, nº. 5: 17-23.

Ayala, M., Polo, J. L. y OrTiz, R. (1989): «Análisis por fluorescencia de Rayos X de útiles metálicos de los yacimientos El Rincón de Almendricos (poblado de llanura) y El Cerro de las Viñas (poblado de altura)». En el XIX Congreso Nacional de Arqueología, Ponencias y comunicaciones. Vol. I, Castellón de la Plana, 1987, Zaragoza: 293-307.

BARrachinA, A. y Neumaier, J. (1996): «Nuevo tipo metálico de los campos de urnas en la Península: la punta de vaina del Pic dels Corbs (Sagunto, Valencia)», Quaderns de Prehistòria i Arqueologia de Castelló, no. 17: 197-206.

Barril, M., Delibes, G. y Ruiz Zapatero, G. (1982): «Moldes de fundición del Bronce Final procedentes de El Regal de Pídola (Huesca)», Trabajos de Prehistoria, XXXVII: 369-383.

Blas Cortina, M. A. de (1981): «Una alabarda procedente del valle del Manzanares (Madrid)», Zephyrus, XXXII-XXXIII: 157-166.

Blas Cortina, M. A. de (1983): La Prehistoria reciente en Asturias. Estudios de Arqueología Asturiana, $\mathrm{n}^{\circ} .1$.

BRANDHERM, D. (1995): Beiträge zur Bewaffnung der Steinkupfer - und der älteren Bronzezeit auf der Iberischen Halbinsel. Studien zur Funktion, Chronologie und Verbreitung der ältermetallzeitlichen Kerbherft-, Griffzungen- und Griffplattenklingen. Freiburg. Edición en microfichas.

BRANDHERM, D. (1998): «Algunas consideraciones acerca de la espada de Guadalajara. ¿Un excepcional depósito desarticulado del Bronce Medio de la Meseta?», Trabajos de Prehistoria, vol. 55, $\mathrm{n}^{\circ} .2$ : 177-184.

BrANDHERM, D. (e.p.): Die Dolche und Stabdolche der Steinkupfer-und der älteren Bronzezeit auf der Iberischen Halbinsel. Prähistorische Bronzefunde, VI, 13.

BRIARD, J. (1965): Les dépôts bretons et l'Age du Bronze Atlantique. Rennes.

Briard, J. (1969): Civilisation des Tumulus Armoricains. Inventaria Archaeologica. France. Fasc. 3.

BRIARD, J. (1976): «Les civilisations de l'Age du Bronce en Armorique», en J. Guilaine (dir.): $L a$ Préhistorie Française. Tomo II. Les civilisations Néolithiques et Protohistoriques de la France. Centre national de la Recherche scientifique. París: 561-574.

BRIARD, J. (1984): Les tumulus d'Armorique. L'Age du Bronce en France 3. Picard. París.

BRIARD, J. y MOHEN, J. P. (1974): «Les tumulus de la forêt de Carnoët à Quimperlé (Finistère)», Antiquités Nationales, $\mathrm{n}^{\circ}$. 6: 46-60.

BRIDGFORD, S. (1998): «British Late Bronze Age swords the metallographic evidence». En C. Mordant, M. Pernot y V. Rychner (eds.): L'atelier du bronzier en Europe du XXe au VIIIe siècle avant notre ère. Du minerai au métal, du metal à l'objet. Actes du colloque international Bronze'96. Neuchâtel et Dijon, 1996. Tomo II (session de Dijon), París, CTHS: 205-217. 
BuDD, P. D. (1991): A metallographic investigation of Eneolithic arsenical copper. Department of Archaeological Sciences. University of Bradford.

CARtailhac, E. (1886): Les Ages Préhistoriques de l'Espagne et du Portugal, París.

Castro Martínez, P., Lull, V. y Micó, R. (1996): Cronología de la Prehistoria Reciente de la Península Ibérica y Baleares (c.2800-900 cal ANE). BAR International Series 652. Oxford.

Castro Nunes, J y Vasco Rodrigues, A. (1957): «Dos nuevas espadas del Bronce Final en Portugal», Zephyrus, número VIII: 279-285.

Chenorkian, R. (1988): Les armes métalliques dans l'art Protohistorique de l'Occident Méditerranéen. Ed. Centre National de la Recherche Scientifique. París.

COFFYN, A. (1976): «Les civilisations de l'Age du Bronze en Aquitine», en J. Guilaine (dir.): $L a$ Préhistorie Française. Tomo II. Les civilisations Néolithiques et Protohistoriques de la France. Centre national de la Recherche scientifique. París: 532-542.

DÉchelette, J. (1910): Manuel d'Archéologie Préhistorique Celtique et Gallo-romaine. Tomo II. Archéologie Celtique ou Protohistorique. Première partie: Age du Bronze. París.

Delibes, G., Avello, J. L. y Rojo, M. A. (1982): «Espadas del Bronce antiguo y medio halladas en la provincia de León», Zephyrus, XXXIV-XXXV: 153-163.

Delibes, G., Fernández Manzano, J., Fontaneda PÉrez, E. y Rovira, S. (1999): Metalurgia de la Edad del Bronce en el Piedemonte Meridional de la Cordillera Cantábrica. La Colección Fontaneda. Zamora.

FERnÁndez MirandA, M., MONTERO, I. y RoviRA, S. (1995): «Los primeros objetos de bronce en el Occidente de Europa», Trabajos de Prehistoria, vol. 52, nº. 1: 57-69.

Ferro Couselo, J. (1941): «Museo Arqueológico de Orense», Memorias de los Museos Provinciales. Madrid: 119-122.

GARcía SÁnChEZ, M. (1963): «El poblado argárico del cerro del Culantrillo, en Gorafe (Granada)», Archivo de Prehistoria Levantina, vol. X: 69-96.

GARcía SÁncheZ, M. y CARRASCO RuS, J. (1979): «Análisis espectográficos de objetos metálicos procedentes de la provincia de Granada», XV Congreso Nacional de Arqueología, Lugo, 1977. Zaragoza: 237-252.

GERLOFF, S. (1975): The Early Bronze Age daggers in Great Britain and a Reconsideration of the Wessex Culture. Prähistorische Bronzefunde, VI, 2. Münich.

Gimbutas, M. (1965): Bronze Age Cultures in Central and Eastern Europe. La Haya.

Gómez Moreno, M. (1949): «Sobre lo argárico granadino», Misceláneas. Primera Serie: la Antigüedad. Madrid: 337-342.

Gómez Ramos, P. (1999): Obtención de metales en la Prehistoria de la Península Ibérica. BAR International Series 753. Oxford.

Gómez RAmos, P. (2000): «De metalurgia prehistórica madrileña». En La Arqueología Madrileña en el final del siglo XX: desde la Prehistoria hasta el año 2000. Coord. Encarnación Ruano y editado por la Asociación Española de Amigos de la Arqueología. XXX Aniversario 1969-1999, nºs. 3940: $167-176$.

GónZAlez Prats (1990): Nueva luz sobre la Protohistoria del Sudeste. Universidad de Alicante.

Guilaine, J. (1972): L'Age du Bronze en Languedoc occidental, Roussillon, Ariège. Mémoires de la Société Préhistorique Française, tomo 9. París.

HARBison, P. (1967): «Mediterranean and Atlantic elements in the Early Bronze Age of Northern Portugal and Galicia», Madrider Mitteilungen, 8: 100-122.

HARRISON, R. (1983): «Notas sobre el empleo de la plata en la cultura argárica del SE. Peninsular». Homenaje al Prof. Martín Almagro Basch. Tomo II. Ministerio de Cultura. Madrid: 17-21.

HEALY, J. (1993): Miniere e metallurgia nel mondo greco e romano. Edit. L'Erma di Bretschneider. 
HuNDT, H.J. (1991): «Gewebereste aus den frühbronzezeitlichen Gräbern von El Argar (Almería)». En H. Schubart y H. Ulreich: Die Funde der Südostspanischen Bronzezeit aus der Sammlung Siret. Madrider Beiträge, 17: 414-431.

INCHAURRANDIETA, R. (1869): «Notice sur la montagne funéraire de La Bastida, province de Murcie (Espagne)». Congrès International d'Anthropologie et d'Archéologie Préhistoriques, $4 .{ }^{a}$ Sesión, Copenhague, 1869: 344-350.

Jover, F. J. y LÓPEZ, J. A. (1997): Arqueología de la muerte. Prácticas funerarias en los límites de El Argar. Publicaciones de la Universidad de Alicante.

Junghans, S., SANGMEISTER, E. y SCHRÖDER, M. (1968): Kupfer und Bronze in der Frühen Metallzeit Europas. Katalog der Analysen Nr. 985-10040. Studien zu den Anfängen der Metallurgie (SAM 2,3). Gebr. Mann Verlag. Berlín.

Junghans, S., SANGMEISTER, E. y SCHRÖDER, M. (1974): Kupfer und Bronze in der Frühen Metallzeit Europas. Katalog der Analysen Nr. 10041-22000 (mit Nachuntersuchungen der Analysen Nr. 1-10040). Studien zu den Anfängen der Metallurgie (SAM 2,4). Gebr. Mann Verlag. Berlín.

KILIAN-DiRLMeIER, I. (1993): Die Schwerter in Griechenland (ausserhalb der Peloponnes), Bulgarien und Albanien. Prähistorische Bronzefunde, IV, 12. Stuttgart.

LEGUINA Y VIDAL, E. de (1914): «La espada española». En: Discursos leídos ante la Real Academia de la Historia. Madrid: 55-56.

LuLL, V. (1983): «La «Cultura» de El Argar (un modelo para el estudio de las formaciones económico-sociales prehistóricas)». Ed. Akal/Universitaria. Madrid.

MaYA, J. L. y Mestres, J. S. (1996): «Approche à la chronologie de l'Âge du Bronze et le Premier Âge du Fer dans la Péninsule Ibérique». En: Absolute Chronology, Archaeological Europe 2500500 BC. Acta Archaeologica, Dinamarca, vol. 67: 251-269.

Mohen, J. P. y BAILloud, G. (1987): La vie quotidienne. Les fouilles du Fort-Harrouard, L'âge du bronze en France-4. Ed. Picard. París.

Montero, I. (1992): Estudio arqueometalúrgico en el Sudeste de la Península Ibérica. Colección Tesis Doctorales de la Universidad Complutense de Madrid.

MONTERO, I. (1994): El origen de la metalurgia en el Sureste peninsular. Instituto de Estudios Almerienses, $\mathrm{n}^{\circ}$. 19. Almería.

Montero, I., Rovira, S. y Gómez Ramos, P. (1995): «Plata argárica», Boletín de la Asociación Española de Amigos de la Arqueología, vol. 35: 97-106.

Nieto, G. y SÁnchez MeSeguer, J. (1980): El Cerro de la Encantada. Granátula de Calatrava (Ciudad Real). Excavaciones Arqueológicas en España, nº. 113. Madrid.

NORTHOVER, J. y RYCHNER, V. (1998): «Bronze Analysis: experience of a comparative programme». En C. Mordant, M. Pernot y V. Rychner (eds.): L'atelier du bronzier en Europe du XXe au VIIIe siècle avant notre ère. Du minerai au métal, du metal à l'objet. Actes du colloque international Bronze'96. Neuchâtel et Dijon, 1996. Tomo I (session de Neuchâtel), París, CTHS: 19-40.

NovÁK, P. (1975): Die Schwerter in der Tschechoslowakei I. Prähistorische Bronzefunde, IV, 4. Münich.

PALOL, P. de (1969): «Una espada de bronce hallada en Villaviudas; provincia de Palencia», Boletín del Seminario de Estudios de Arte y Arqueología, Valladolid, XXXIV-XXXV: 295-298.

PÉReZ De BARRAdAS, J. (1936): «Nuevos estudios sobre Prehistoria madrileña I. La colección Bento», Archivo de Prehistoria madrileña, vol. IV-VI. 1933-1935. Madrid: 1-90.

PERONI, V. B. (1970): Die Schwerter in Italien. Le spade nell'Italia continentale. Prähistorische Bronzefunde, IV, 1. Münich.

PERONI, R. (1971): L'Età del Bronzo nella Penisola Italiana. I. L'antica età del bronzo. Studi XIX de la Accademia Toscana di Scienze e Lettere «La Colombaria». Florencia.

RiQuelme, J. (1999): «La Cueva de Las Ventañas. Piñar (Granada). Recuperación e investigación del Patrimonio Arqueológico», Revista de Arqueología, año XX, nº. 222: 12-19. 
Rodríguez, J. A., RoJo, M. y Fernández, J. M. a (1988): «Una nueva espada del Bronce Medio hallada en Villaviudas (Palencia)», Boletín del Seminario de Estudios de Arte y Arqueología, Valladolid, LIV: 219-223.

RoudiL, J. L. (1972): L'Age du Bronze en Languedoc Oriental. Mémoires de la Société Préhistorique Française, tomo 10. París.

RovirA, S. (1995): «Estudio arqueometalúrgico del depósito de la Ría de Huelva». En M. ${ }^{a}$ L. Ruiz-Gálvez (edit.): Ritos de paso y puntos de paso. La Ría de Huelva en el mundo del Bronce Final europeo. Complutum, Extra no. 5, Editorial Complutense, Madrid: 33-57.

Rovira, S., Montero, I. y CONSUEGRA, S. (1997): Las primeras etapas metalúrgicas en la Península Ibérica. I. Análisis de materiales. Instituto Universitario José Ortega y Gasset. Madrid.

Rovira, S., Montero, I. y Gómez Ramos, P. (1998): «The Beginning of the use of metals in Spain». En: Proceedings The Fourth International Conference on the Beginning of the Use of Metals and Alloys. BUMA-IV Organizing Committee. The Japan Institute of Metals. Matsue, Shimane, Japón: 153-158.

Rovira HortalÀ, C. (1998): «Activités métallurgiques à l'extrême nord-est de la Péninsule Ibérique pendant l'Âge du Bronze Ancien-Moyen. Le site de Mingerri (Lleida)». En C. Mordant, M. Pernot y V. Rychner (eds.): L'atelier du bronzier en Europe du XXe au VIIIe siècle avant notre ère. Du minerai au métal, du metal à l'objet. Actes du colloque international Bronze'96. Neuchâtel et Dijon, 1996. Tomo II (session de Dijon), París, CTHS: 241-247.

Ruiz Morales, J. A. y Molina PovedA, C. (1996): «La espada argárica de La Herradura (Granada)», Quaderns de Prehistòria i Arqueologia de Castelló, $\mathrm{n}^{\circ}$. 17: 175-181.

SANCHES, M. J. (1995): «Alabardas de tipo Carrapatas». En: A Idade do Bronze em Portugal. Discursos de poder. Secretaria de Estado da Cultura, Instituto Português de Museus y Museu Nacional de Arqueologia: 29-31.

Schubart, H. (1973): «Las alabardas tipo Montejícar». En: Estudios dedicados al Prof. Dr. Luis Pericot. Publicaciones eventuales $\mathrm{n}^{\circ}$. 23. Instituto de Arqueología y Prehistoria de la Universidad de Barcelona: 247-269.

Schubart, H. y ARTeAgA, O. (1986): «Fundamentos arqueológicos para el estudio socioeconómico y cultural del área de El Argar». En: Actas del Congreso «Homenaje a Luis Siret (19341984)», Cuevas del Almanzora, 1984. Consejería de Cultura de la Junta de Andalucía. Dirección General de Bellas Artes: 289-307.

SchubART, H. y UlReich, H (1991): Die Funde der Südostspanischen Bronzezeit aus der Sammlung Siret. Madrider Beiträge, 17.

SHALEV, S. (1988): «Redating the «Philistine sword» at the British Museum: a case study in typology and technology», Oxford Journal of Archaeology, 7 (3): 303-311.

Simón GARCíA, J. L. (1988): «Materiales argáricos en museos alicantinos», Anales de Prehistoria y Arqueología de la Universidad de Murcia, no. 4: 55-70.

SIRET, E. y L. (1890): «Las primeras edades del metal en el Sudeste de España». Ed. Martorell. Barcelona.

SIRET, L. (1913): Questions de chronologie et d'etnographie ibériques. Tomo I. París.

StANLEY, C. (1973): «An Examination of the Arsenic-Rich Coating on a Bronze Bull from Horoztepe». En W. Young (ed.): Application of Science in Examination of Works of Art. Museum of Fine Arts. Boston.

Tylecote, R. F. (1976): A History of Metallurgy. Edit. The Metals Society. Londres.

VÁZQUEZ DE PARGA, L. (1935): «Colección de antigüedades que perteneció a D. Aureliano Fernández-Guerra». Adquisiciones en 1933 del Museo Arqueológico Nacional. Madrid. 